\title{
Angiopoietin 1 release from Human Neutrophils is Independent from Neutrophil Extracellular Traps (NETs)
}

\section{Elcha Charles}

Montreal Heart Institute

\section{Benjamin Dumont}

Montreal Heart Institute

\section{Steven Bonneau}

Montreal Heart Institute

Paul-Eduard Neagoe

Montreal Heart Institute

Louis Villeneuve

Montreal Heart Institute

\section{Agnès Rakel}

Centre Hospitalier de l'Université de Montréal

\section{Michel White}

Montreal Heart Institute

Martin Sirois ( $\nabla$ martin.sirois@icm-mhi.org )

Montreal Heart Institute

\section{Research Article}

Keywords: angiopoietin 1, neutrophil, NETs, heart failure, type 2 diabetes, calprotectin (S100A8/A9), Inflammation

Posted Date: January 25th, 2021

DOI: https://doi.org/10.21203/rs.3.rs-147798/v1

License: (c) (1) This work is licensed under a Creative Commons Attribution 4.0 International License. Read Full License

Version of Record: A version of this preprint was published at BMC Immunology on August 3rd, 2021. See the published version at https://doi.org/10.1186/s12865-021-00442-8. 


\section{Abstract}

Background: Neutrophils induce the synthesis and release of angiopoietin 1 (Ang1), a cytosolic growth factor involved in angiogenesis and capable of inducing several pro-inflammatory activities in neutrophils. Neutrophils also synthesize and release neutrophil extracellular traps (NETs), comprised from decondensed nuclear DNA filaments carrying proteins such as neutrophil elastase (NE), myeloperoxidase (MPO), proteinase 3 (PR3) and calprotectin (S100A8/S100A9), which together, contribute to the innate immune response against pathogens (e.g., bacteria). NETs are involved in various pathological conditions through pro-inflammatory, pro-thrombotic and endothelial dysfunction effects and have recently been found in heart failure (HF) and type 2 diabetes (T2DM) patients. The aim of the present study was to investigate the role of NETs on the synthesis and release of Ang1 by the neutrophils in patients with T2DM and HF with preserved ejection fraction (HFpEF) (stable or acute decompensated; ADHFpEF) with or without T2DM.

Results: Our data show that at basal level (PBS) and upon treatment with LPS, levels of NETs are slightly increased in patients suffering from T2DM, HFpEF \pm T2DM and ADHF w/o T2DM, whereas this increase was significant in ADHFpEF + T2DM patients compared to healthy control (HC) volunteers and ADHFpEF without T2DM. We also observed that treatments with PMA or A23187 increase the synthesis of Ang1 (from 150 to $250 \%$ ) in $\mathrm{HC}$ and this effect is amplified in T2DM and in all cohorts of HF patients. Ang1 is completely released (100\%) by neutrophils of all groups and does not bind to NETs as opposed to calprotectin.

Conclusions: Our study suggests that severely ill patients with HFpEF and diabetes synthesize and release a greater abundance of NETs while Ang1 exocytosis is independent of NETs synthesis.

\section{Background}

Neutrophil extracellular traps (NETs) are composed of double-stranded DNA decorated with cytosolic and granule-derived pro-inflammatory cytokines and enzymes (1). NETs are in response to inflammatory stimuli and carry cytoplasmic, granular and nuclear proteins (e.g. calprotectin; S100A8/A9, myeloperoxidase (MPO), neutrophil elastase (NE), histones and others) (2), contributing to the innate immune response against pathogens $(1,3,4)$. Although NETs were initially described as an antimicrobial mechanism of neutrophils and implicated in infectious disorders (1), other studies reported NETs involvement in the pathophysiology of non-infectious conditions such as thrombosis $(5,6)$, fibrosis $(7,8)$, inflammation (9) and cardiovascular disorders (10). Even though there are common proteins linked to NETs, the variety and quantity of proteins bound to NETs can vary depending on the stimuli and proinflammatory conditions $(11,12)$.

Heart failure (HF) is a pro-inflammatory condition, in which the magnitude of inflammation is associated with the disease severity, being maximal in acute decompensated heart failure (ADHF) patients. Lately, we and other groups reported an increase of NETs formation, either circulating or under in vitro neutrophil 
stimulation in type 2 diabetic (T2DM) patients (13-15) and in patients suffering from HF with or without T2DM (15). HF classification is based on left ventricular ejection fraction (LVEF), which can be reduced (HFrEF, LVEF $\leq 40 \%$ ) or preserved (HFpEF, LVEF $\geq 50 \%$ ), each with distinct phenotypes (16). HFrEF is typically associated to primary myocardial lesion (e.g. myocardial infarction) leading to inadequate contractility of the left ventricle (16). In contrast, HFpEF is a heterogeneous and multiorgan disorder, influenced by multiple comorbidities, including obesity, hypertension and T2DM. These conditions can lead to low-grade systemic inflammation, extensive endothelial and cardiac microvascular dysfunction, which can ultimately induce myocardial leukocytes migration, ventricular fibrosis, stiffening and dysfunction $(17,18)$. In these conditions, impaired angiogenesis can occur and is mediated by growth factors such as vascular endothelial growth factor (VEGF) and angiopoietins (Ang). Over the last years, HFpEF prevalence outreached HFrEF cases, representing now $>50 \%$ of all HF patients $(19,20)$ and the attempts to transpose life-saving therapies from HFrEF to HFpEF have failed $(21,22)$. It is therefore critical to find potential treatments for these patients.

There is also an increased incidence of ADHF, defined by a worsening of stable chronic HF (23). This increases the rate of hospitalization and death in patients $>65$ years old, who also have a $40 \%$ prevalence of T2DM (19). The management of ADHF is different from stable HF (24), hence the importance of studying this pathology separately.

Calprotectin (S100A8/A9), a $36 \mathrm{kDa}$ heterodimeric complex, is a cytosolic glycoprotein with two calcium binding of the $\mathrm{S} 100$ protein family and is constitutively expressed in neutrophils, monocytes, and macrophages (25-28). Calprotectin, known for its antimicrobial functions $(27,28)$, is carried by NETs (3) and used as an inflammatory marker in the diagnostic of non-infectious inflammatory disorders such as arthritis, bowel $(29,30)$ and cardiovascular diseases (e.g. myocardial infarction, unstable angina and chronic HF) (31). Angiopoietin 1 (Ang1) is a secreted 70-kDa glycoprotein constitutively expressed by vascular smooth muscle cells (32), platelets $(33)$, pericytes, monocytes and neutrophils $(34,35)$ and a key regulator for angiogenesis, through vascular stabilisation and maturation (36). Ang1 may also play a role in endothelial dysfunction associated with cardiovascular diseases such as HF and T2DM $(37,38)$. Yet, it is unknow if the release of Ang1 by the neutrophils is associated to NETs synthesis and release.

The objective of this study was to determine the capacity of various inflammatory mediators (LPS, PMA and A23187) to induce NETs, Ang1 and calprotectin synthesis and release, and if Ang1 can bind to NETs, using calprotectin as a positive control, from neutrophils of patients with stable or decompensated $\mathrm{HF}$ with or w/o T2DM compared with healthy control $(\mathrm{HC})$ volunteers.

\section{Results}

The clinical characteristics of the study population are presented in Table 1. The study population consisted of 34 healthy control (HC) volunteers, 8 patients with T2DM and without HF-pEF, 12 patients with HFpEF and with stable symptoms (7 with T2DM) and 13 patients with ADHFpEF (6 with T2DM). Most HF and ADHF patients had a HF caused by cardiomyopathy. All patients with stable HF and a 
majority of patients with ADHF + T2DM suffered from hypertension. There was no significant difference in LV ejection fraction between stable or ADHF patients with or without diabetes. All T2DM patients were treated with statins. The majority ( $>70 \%$ ) of stable HF or ADHF patients were treated by oral anticoagulants. 
Table 1

Baseline patients characteristics.

\begin{tabular}{|c|c|c|c|c|c|c|}
\hline & $\begin{array}{l}\mathrm{HC} \\
(n=34)\end{array}$ & $\begin{array}{l}\text { T2DM group } \\
(n=8)\end{array}$ & $\begin{array}{l}\text { Stable HFpEF } \\
(n=5)\end{array}$ & $\begin{array}{l}\text { Stable } \\
\text { HFpEF } \\
\begin{array}{l}+ \text { T2DM } \\
(n=7)\end{array}\end{array}$ & $\begin{array}{l}\text { ADHFpEF } \\
(n=7)\end{array}$ & $\begin{array}{l}\text { ADHFpEF } \\
\begin{array}{l}\text { +T2DM } \\
(n=6)\end{array}\end{array}$ \\
\hline Age $(y)$ & & $68 \pm 1.7$ & $75 \pm 3.3$ & $71 \pm 3.2$ & $82 \pm 3.0^{*}$ & $73 \pm 3.5$ \\
\hline Males $n(\%)$ & $\begin{array}{l}20 \\
(58.8 \%)\end{array}$ & $6(75 \%)$ & $2(40 \%)$ & $\begin{array}{l}4 \\
(57.1 \%)\end{array}$ & $2(28.6 \%)$ & $4(66.7 \%)$ \\
\hline \multicolumn{7}{|c|}{ NYHA classification n (\%) } \\
\hline class I & $\mathrm{n} / \mathrm{a}$ & $\mathrm{n} / \mathrm{a}$ & $0(0 \%)$ & $\begin{array}{l}1 \\
(14.3 \%)\end{array}$ & $0(0 \%)$ & $0(0 \%)$ \\
\hline class II & $\mathrm{n} / \mathrm{a}$ & $\mathrm{n} / \mathrm{a}$ & $3(60 \%)$ & $\begin{array}{l}5 \\
\text { (71.4\%) }\end{array}$ & $2(28.6 \%)$ & $1(16.7 \%)$ \\
\hline class III & $\mathrm{n} / \mathrm{a}$ & $\mathrm{n} / \mathrm{a}$ & $2(40 \%)$ & $\begin{array}{l}1 \\
(14.3 \%)\end{array}$ & $2(28.6 \%)$ & $2(33.3 \%)$ \\
\hline class IV & $\mathrm{n} / \mathrm{a}$ & $\mathrm{n} / \mathrm{a}$ & $0(0 \%)$ & $0(0 \%)$ & $2(28.6 \%)$ & $2(33.3 \%)$ \\
\hline \multicolumn{7}{|l|}{ Etiology n (\%) } \\
\hline Ischemia & $\mathrm{n} / \mathrm{a}$ & $n / a$ & $0(0 \%)$ & $\begin{array}{l}1 \\
(14.3 \%)\end{array}$ & $0(0 \%)$ & $2(33.3 \%)$ \\
\hline Cardiomyopathy & $\mathrm{n} / \mathrm{a}$ & $\mathrm{n} / \mathrm{a}$ & $1(20 \%)$ & $\begin{array}{l}5 \\
(71.4 \%)\end{array}$ & $3(42.9 \%)$ & $1(16.7 \%)$ \\
\hline Valvular & $\mathrm{n} / \mathrm{a}$ & $\mathrm{n} / \mathrm{a}$ & $0(0 \%)$ & $\begin{array}{l}3 \\
(42.9 \%)\end{array}$ & $1(14.3 \%)$ & $2(33.3 \%)$ \\
\hline Others & $\mathrm{n} / \mathrm{a}$ & $\mathrm{n} / \mathrm{a}$ & $4(80 \%)$ & $0(0 \%)$ & $4(57.1 \%)$ & $0(\%)$ \\
\hline $\operatorname{LVEF}(\%)$ & $\mathrm{n} / \mathrm{a}$ & $\mathrm{n} / \mathrm{a}$ & $54 \pm 2.1$ & $58 \pm 1.5$ & $57 \pm 2.6$ & $55 \pm 1.3$ \\
\hline Hypertension & $n / a$ & $6(75 \%)$ & $5(100 \%)$ & $7(100 \%)$ & $4(57.1 \%)$ & $6(100 \%)$ \\
\hline Dyslipidemia & $\mathrm{n} / \mathrm{a}$ & $7(87.5 \%)$ & $1(20 \%)$ & $\begin{array}{l}4 \\
(57.1 \%)\end{array}$ & $3(42.9 \%)$ & 5 (83.3\%) \\
\hline Stroke & $\mathrm{n} / \mathrm{a}$ & $0(0.0 \%)$ & $0(0.0 \%)$ & $0(0.0 \%)$ & $0(0.0 \%)$ & $0(0.0 \%)$ \\
\hline
\end{tabular}

$\mathrm{HC}$, healthy controls; HFpEF, heart failure with preserved ejection fraction; ADHF, acute decompensated heart failure; T2DM, type-2 diabetes mellitus; NYHA, New York Health Association; LVEF, left ventricular ejection fraction; ACEi, angiotensin-converting enzyme inhibitor; $A R B$, angiotensin receptor blocker; DPP-4, dipeptidyl peptidase 4; GLP-1, glucagon-like peptide 1; SGLT2, sodiumglucose co-transporter-2. Continuous variables are shown as mean \pm standard error mean and categorical variables as number (\%). Anti-platelets included aspirin,clopidogrel, prasugrel, or ticagrelor or a combination of these. ${ }^{\star} \mathrm{p}<0.05$ vs T2DM 


\begin{tabular}{|c|c|c|c|c|c|c|}
\hline & \multicolumn{3}{|l|}{$(n=34)$} & \multicolumn{2}{|l|}{$\begin{array}{l}+ \text { T2DM } \\
(n=7)\end{array}$} & $\begin{array}{l}\text { ADHFpEF } \\
+ \text { T2DM } \\
(n=6)\end{array}$ \\
\hline $\begin{array}{l}\text { Creatinine } \\
(\mu \mathrm{mol} / \mathrm{l})\end{array}$ & $\mathrm{n} / \mathrm{a}$ & $86.7 \pm 8.6$ & $147 \pm 43$ & $146 \pm 17$ & $127 \pm 21$ & $166 \pm 26$ \\
\hline $\begin{array}{l}\text { Glucose } \\
(\mathrm{mmol} / \mathrm{l})\end{array}$ & $\mathrm{n} / \mathrm{a}$ & $9.0 \pm 0.7$ & $5.7 \pm 0.6 *$ & $6.9 \pm 0.6$ & $6.4 \pm 0.6$ & $8.0 \pm 0.6$ \\
\hline $\begin{array}{l}\text { Triglyceride } \\
(\mathrm{mmol} / \mathrm{l})\end{array}$ & $\mathrm{n} / \mathrm{a}$ & $1.35 \pm 0.19$ & $1.02 \pm 0.12$ & $\begin{array}{l}2.06 \pm \\
0.56\end{array}$ & & $\begin{array}{l}1.43 \pm \\
0.13\end{array}$ \\
\hline LDL (mmol/l) & $\mathrm{n} / \mathrm{a}$ & $1.80 \pm 0.12$ & $2.23 \pm 0.80$ & $\begin{array}{l}1.09 \pm \\
0.23\end{array}$ & & $\begin{array}{l}1.64 \pm \\
0.50\end{array}$ \\
\hline \multicolumn{7}{|l|}{ Medication n (\%) } \\
\hline ACEi & $\mathrm{n} / \mathrm{a}$ & 3 (37.5\%) & $0(0.0 \%)$ & $\begin{array}{l}1 \\
(14.3 \%)\end{array}$ & $0(0.0 \%)$ & $1(16.7 \%)$ \\
\hline ARBs & $\mathrm{n} / \mathrm{a}$ & 5 (62.5\%) & $0(0.0 \%)$ & $\begin{array}{l}2 \\
(28.6 \%)\end{array}$ & $1(14.3 \%)$ & $0(0.0 \%)$ \\
\hline$\beta$-blockers & $\mathrm{n} / \mathrm{a}$ & 3 (37.5\%) & $3(60 \%)$ & $\begin{array}{l}5 \\
(71.4 \%)\end{array}$ & $5(71.4 \%)$ & $5(83.3 \%)$ \\
\hline Diuretic agents & $\mathrm{n} / \mathrm{a}$ & $2(25 \%)$ & $5(100 \%)$ & $7(100 \%)$ & $5(71.4 \%)$ & $6(100 \%)$ \\
\hline Statins & $\mathrm{n} / \mathrm{a}$ & $8(100 \%)$ & $2(40 \%)$ & $\begin{array}{l}3 \\
(42.9 \%)\end{array}$ & $2(28.6 \%)$ & $5(83.3 \%)$ \\
\hline Anticoagulants & $\mathrm{n} / \mathrm{a}$ & $0(0.0 \%)$ & $5(100 \%)$ & $\begin{array}{l}4 \\
(57.1 \%)\end{array}$ & $6(85.7 \%)$ & $3(50.0 \%)$ \\
\hline Sulfonylureas & $\mathrm{n} / \mathrm{a}$ & 3 (37.5\%) & $0(0.0 \%)$ & $\begin{array}{l}1 \\
(14.3 \%)\end{array}$ & $0(0.0 \%)$ & $2(33.3 \%)$ \\
\hline DDP-4 inhibitors & $\mathrm{n} / \mathrm{a}$ & $5(62.5 \%)$ & $0(0.0 \%)$ & $\begin{array}{l}4 \\
(57.1 \%)\end{array}$ & $0(0.0 \%)$ & $1(16.7 \%)$ \\
\hline GLP-1 agonists & $\mathrm{n} / \mathrm{a}$ & $2(25 \%)$ & $0(0.0 \%)$ & $0(0.0 \%)$ & $0(0.0 \%)$ & $0(0.0 \%)$ \\
\hline $\begin{array}{l}\text { SGLT-2 } \\
\text { inhibitors }\end{array}$ & $\mathrm{n} / \mathrm{a}$ & $2(25 \%)$ & $0(0.0 \%)$ & $\begin{array}{l}2 \\
(28.6 \%)\end{array}$ & $0(0.0 \%)$ & $1(16.7 \%)$ \\
\hline Metformin & $\mathrm{n} / \mathrm{a}$ & 7 (87.5\%) & $1(20 \%)$ & $\begin{array}{l}4 \\
(57.1 \%)\end{array}$ & $0(0.0 \%)$ & $1(16.7 \%)$ \\
\hline \multicolumn{7}{|c|}{$\begin{array}{l}\text { HC, healthy controls; HFpEF, heart failure with preserved ejection fraction; ADHF, acute } \\
\text { decompensated heart failure; T2DM, type-2 diabetes mellitus; NYHA, New York Health Association; } \\
\text { LVEF, left ventricular ejection fraction; ACEi, angiotensin-converting enzyme inhibitor; ARB, angiotensin } \\
\text { receptor blocker; DPP-4, dipeptidyl peptidase 4; GLP-1, glucagon-like peptide 1; SGLT2, sodium- } \\
\text { glucose co-transporter-2. Continuous variables are shown as mean } \pm \text { standard error mean and } \\
\text { categorical variables as number (\%). Anti-platelets included aspirin,clopidogrel, prasugrel, or ticagrelor } \\
\text { or a combination of these. *p }<0.05 \text { vs T2DM }\end{array}$} \\
\hline
\end{tabular}




\begin{tabular}{|c|c|c|c|c|c|c|}
\hline & $\begin{array}{l}\mathrm{HC} \\
(n=34)\end{array}$ & $\begin{array}{l}\text { T2DM group } \\
(n=8)\end{array}$ & $\begin{array}{l}\text { Stable HFpEF } \\
(n=5)\end{array}$ & $\begin{array}{l}\text { Stable } \\
\text { HFpEF } \\
+ \text { +T2DM } \\
(n=7)\end{array}$ & $\begin{array}{l}\text { ADHFpEF } \\
(\mathrm{n}=7)\end{array}$ & $\begin{array}{l}\text { ADHFpEF } \\
+ \text { T2DM } \\
(n=6)\end{array}$ \\
\hline Insulin & $\mathrm{n} / \mathrm{a}$ & $1(12.5 \%)$ & $0(0.0 \%)$ & $\begin{array}{l}2 \\
(28.6 \%)\end{array}$ & $0(0.0 \%)$ & 2 (33.3\%) \\
\hline \multicolumn{7}{|c|}{$\begin{array}{l}\text { HC, healthy controls; HFpEF, heart failure with preserved ejection fraction; ADHF, acute } \\
\text { decompensated heart failure; T2DM, type-2 diabetes mellitus; NYHA, New York Health Association; } \\
\text { LVEF, left ventricular ejection fraction; ACEi, angiotensin-converting enzyme inhibitor; ARB, angiotensin } \\
\text { receptor blocker; DPP-4, dipeptidyl peptidase 4; GLP-1, glucagon-like peptide } 1 \text {; SGLT2, sodium- } \\
\text { glucose co-transporter-2. Continuous variables are shown as mean } \pm \text { standard error mean and } \\
\text { categorical variables as number (\%). Anti-platelets included aspirin,clopidogrel, prasugrel, or ticagrelor } \\
\text { or a combination of these. *p }<0.05 \text { vs T2DM }\end{array}$} \\
\hline
\end{tabular}

\section{NETs release by neutrophils}

The rate of NETs synthesis and release for all 6 cohorts (HC, T2DM, stable HFpEF \pm T2DM and ADHFpEF \pm T2DM patients) is presented in Fig. 1. The basal value of NETs (quantified as dsDNA) released by neutrophils from HC treated with PBS (basal control) for 3 hours was $63.6 \pm 9.6 \mathrm{ng} / 5 \times 10^{6}$ neutrophils $/ \mathrm{mL}$ (Fig. 1). In HC, we observed a significant 4.2-fold (265 vs $63.6 \mathrm{ng} / \mathrm{mL}$ ) and 9.4-fold (597 vs $63.6 \mathrm{ng} / \mathrm{mL}$ ) NETs increase post-stimulation with PMA and A23187 respectively compared to PBS, whereas LPS did not increase NETs release. A similar pattern was observed in PMA- and A23187-stimulated neutrophils from T2DM patients, stable HFpEF \pm T2DM and ADHFpEF without T2DM (Fig. 1). Basal and LPSstimulated neutrophils from ADHFpEF + T2DM patients released significantly more NETs (2.4-fold (152 vs $63.6 \mathrm{ng} / \mathrm{mL}$ ) and 2.9-fold (199 vs $63.6 \mathrm{ng} / \mathrm{mL}$ ) respectively), while the A23187 stimulation released a significant lower quantity of NETs ( $47 \%$ decrease; $316 \mathrm{vs} 597 \mathrm{ng} / \mathrm{mL}$ ) compared to HC. When comparing ADHF w/o T2DM vs ADHF + T2DM, we observed that NETs release increased in basal condition (3.2-fold; 152 vs $47.4 \mathrm{ng} / \mathrm{mL}$ ) and LPS-stimulated neutrophils (2.5-fold; 199 vs $81.1 \mathrm{ng} / \mathrm{mL}$ ) .

\section{Angiopoietin 1 release, intracellular content and NETs binding in neutrophils}

We assessed the Ang1 release, intracellular content and binding capacity to released NETs in isolated neutrophils from all 6 cohorts upon stimulation with PBS, LPS, PMA and A23187 for 3 hours. The postisolation intracellular content of Ang1 (T0) was $112 \pm 11 \mathrm{pg} / 5 \times 10^{6}$ neutrophils $/ \mathrm{mL}$ from HC. There was a non-significant decrease in Ang 1 concentrations at T0 from neutrophils of all five patients' cohorts (Table 2). After a 3-hour treatment with PBS, LPS, PMA or A23187, the Ang1 content released by neutrophils from all cohorts was higher than before treatment (T0), but only significant in PBS- (1.56-fold; 175 vs $112 \mathrm{pg} / \mathrm{mL}$ ), PMA- (1.98-fold; 222 vs $112 \mathrm{pg} / \mathrm{mL}$ ) and A23187- (1.80-fold; 202 vs $112 \mathrm{pg} / \mathrm{mL}$ ) stimulated neutrophils from HC. The concentration of Ang1 detected intracellularly or bound to NETs following a 3-hour stimulation with all agonists in all 6 cohorts were below the lower limit of quantitation (LLOQ; $<156 \mathrm{pg} / \mathrm{mL}$ ), and extrapolated from the ELISA standard curve. Therefore, the total amount of 
Ang1 detected at 3 hours post-treatment was considered as being almost completely released, indicating a significant increase of Ang1 synthesis (up to 1.98-fold; $202 \mathrm{vs} 112 \mathrm{pg} / \mathrm{mL}$ ) in neutrophils from $\mathrm{HC}$, and this effect was amplified in PMA and A23187 stimulated neutrophils from T2DM patients (up to 2.91fold; $201 \mathrm{vs} 69 \mathrm{pg} / \mathrm{mL}$ ). In all other cohorts, independently from the agonists used, Ang1 synthesis of also increased (up to 3.18-fold; 216 vs 101 pg/mL in HFpEF PMA-stimulated neutrophils) (Table 2). 
Table 2

Angiopoietin 1 synthesis and release from neutrophils

\begin{tabular}{|c|c|c|c|c|c|c|c|}
\hline & & $\mathrm{HC}$ & T2DM & HFpEF & $\begin{array}{l}\text { HFpEF } \\
\text { + T2DM }\end{array}$ & ADHFpEF & $\begin{array}{l}\text { ADHFpEF + } \\
\text { T2DM }\end{array}$ \\
\hline & & $(n=22)$ & $(n=8)$ & $(n=5)$ & $(n=7)$ & $(n=5)$ & $(n=4-5)$ \\
\hline T0 & $\begin{array}{l}\left(\mathrm{pg} / 5 \times 10^{6}\right. \\
\text { cells) }\end{array}$ & $112 \pm 11$ & $69 \pm 8.7$ & $61 \pm 11$ & $89 \pm 14$ & $101 \pm 40$ & $74 \pm 23$ \\
\hline \multirow{12}{*}{$\begin{array}{l}\mathrm{T}= \\
3 \mathrm{H}\end{array}$} & \multicolumn{7}{|c|}{ 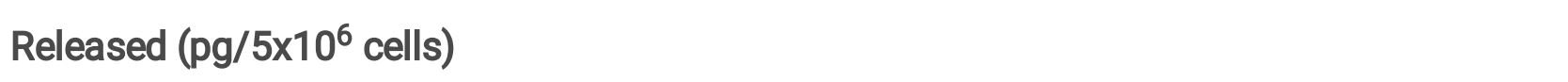 } \\
\hline & PBS & $\begin{array}{l}175 \pm \\
19 \S \S\end{array}$ & $169 \pm 39$ & $147 \pm 33$ & $125 \pm 32$ & $188 \pm 62$ & $105 \pm 24$ \\
\hline & LPS & $149 \pm 15$ & $163 \pm 37$ & $146 \pm 29$ & $120 \pm 35$ & $165 \pm 67$ & $102 \pm 32$ \\
\hline & PMA & $\begin{array}{l}222 \pm \\
31 \S \S\end{array}$ & $\begin{array}{l}201 \pm \\
36 \S \S\end{array}$ & $194 \pm 53$ & $175 \pm 42$ & $216 \pm 59$ & $133 \pm 29$ \\
\hline & A23187 & $\begin{array}{l}202 \pm \\
26 \S\end{array}$ & $\begin{array}{l}185 \pm \\
31^{\S}\end{array}$ & $183 \pm 37$ & $143 \pm 44$ & $187 \pm 66$ & $122 \pm 37$ \\
\hline & \multicolumn{7}{|c|}{ Intracellular $\left(\mathrm{pg} / 5 \times 10^{6} \mathrm{cells}\right) * \star \star$} \\
\hline & PBS & $\begin{array}{l}19.2 \pm \\
3.3\end{array}$ & $\begin{array}{l}17.1 \pm \\
3.4\end{array}$ & $\begin{array}{l}14.4 \pm \\
8.8\end{array}$ & $6.7 \pm 4.4$ & $\begin{array}{l}16.8 \pm \\
11.0\end{array}$ & $6.4 \pm 6.2$ \\
\hline & LPS & $\begin{array}{l}17.8 \pm \\
3.1\end{array}$ & $\begin{array}{l}20.6 \pm \\
4.3\end{array}$ & $\begin{array}{l}14.7 \pm \\
9.1\end{array}$ & $8.3 \pm 5.8$ & $7.6 \pm 7.6$ & $8.5 \pm 8.5$ \\
\hline & PMA & $\begin{array}{l}29.9 \pm \\
4.1\end{array}$ & $\begin{array}{l}24.1 \pm \\
4.8\end{array}$ & $\begin{array}{l}14.3 \pm \\
8.8\end{array}$ & $\begin{array}{l}14.4 \pm \\
4.5\end{array}$ & $\begin{array}{l}24.5 \pm \\
12.0\end{array}$ & $16.8 \pm 8.1$ \\
\hline & A23187 & $\begin{array}{l}21.5 \pm \\
3.8\end{array}$ & $\begin{array}{l}20.9 \pm \\
4.1\end{array}$ & $\begin{array}{l}6.45 \pm \\
6.4\end{array}$ & $9.1 \pm 4.9$ & $13.5 \pm 6.5$ & $13.5 \pm 7.2$ \\
\hline & \multicolumn{7}{|c|}{ Bound to NETs $\left(\mathrm{pg} / 5 \times 10^{6} \mathrm{cells}\right) * * \star$} \\
\hline & PBS & 0 & $\begin{array}{l}0.55 \pm \\
0.55\end{array}$ & $\begin{array}{l}0.74 \pm \\
0.74\end{array}$ & 0 & $\begin{array}{l}0.22 \pm \\
0.22\end{array}$ & 0 \\
\hline
\end{tabular}

Isolated neutrophils $\left(5 \times 10^{6} / \mathrm{ml}\right)$ from healthy controls $(\mathrm{HC}), \mathrm{T} 2 \mathrm{DM}$, stable HFpEF \pm T2DM and ADHFpEF \pm T2DM patients were incubated at $37^{\circ} \mathrm{C}$ for 3 hours with different agonists (PBS control, PMA, LPS and A23187). By ELISA, we quantified Ang1 from unstimulated neutrophils (TO) and stimulated neutrophils. Total Ang1 corresponds to the addition of Ang1 released, intracellular and bound to NETs. *** Values for Intracellular and Bound to NETs are shown, but are below the LLOQ (lower limit of quantitation), therefore are not included in the statistical analyses. $\varsigma_{p}<0.05, \varsigma_{p}<0.01$

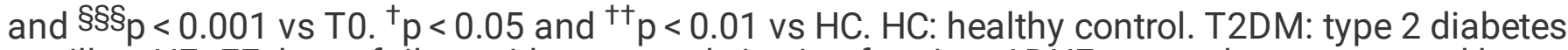
metillus. HFpEF: heart failure with preserved ejection fraction. ADHF: acute decompensated heart failure. 


\begin{tabular}{|c|c|c|c|c|c|c|}
\hline & $\mathrm{HC}$ & T2DM & HFpEF & $\begin{array}{l}\text { HFpEF } \\
+ \text { T2DM }\end{array}$ & ADHFpEF & $\begin{array}{l}\text { ADHFpEF + } \\
\text { T2DM }\end{array}$ \\
\hline & $(n=22)$ & $(n=8)$ & $(n=5)$ & $(n=7)$ & $(n=5)$ & $(n=4-5)$ \\
\hline LPS & 0 & $\begin{array}{l}5.25 \pm \\
4.72\end{array}$ & 0 & $\begin{array}{l}1.19 \pm \\
1.19\end{array}$ & $\begin{array}{l}1.69 \pm \\
1.50\end{array}$ & 0 \\
\hline PMA & 0 & $\begin{array}{l}0.42 \pm \\
0.42\end{array}$ & 0 & 0 & 0 & 0 \\
\hline A23187 & $\begin{array}{l}0.25 \pm \\
0.25\end{array}$ & $\begin{array}{l}0.32 \pm \\
0.32\end{array}$ & 0 & 0 & 0 & 0 \\
\hline Total (pg/ & 5 cells) & & & & & \\
\hline PBS & $\begin{array}{l}175 \pm \\
19 \S \S\end{array}$ & $169 \pm 39$ & $147 \pm 33$ & $125 \pm 32$ & $188 \pm 65$ & $105 \pm 24$ \\
\hline LPS & $149 \pm 15$ & $163 \pm 37$ & $146 \pm 29$ & $120 \pm 35$ & $165 \pm 73$ & $102 \pm 32$ \\
\hline PMA & $\begin{array}{l}222 \pm \\
31 \S \S\end{array}$ & $\begin{array}{l}201 \pm \\
36 \S \S\end{array}$ & $194 \pm 53$ & $175 \pm 42$ & $216 \pm 58$ & $133 \pm 29$ \\
\hline A23187 & $\begin{array}{l}202 \pm \\
26^{\S}\end{array}$ & $\begin{array}{l}185 \pm \\
31^{\S}\end{array}$ & $183 \pm 37$ & $143 \pm 44$ & $187 \pm 71$ & $122 \pm 37$ \\
\hline $\begin{array}{l}\text { Isolated neutrophi } \\
\text { ADHFpEF } \pm \text { T2DM } \\
\text { PMA, LPS and A2 } \\
\text { stimulated neutro } \\
\text { bound to NETs. * } \\
\text { (lower limit of qua } \\
\text { and } \$ \$ \S \mathrm{p}<0.001 \mathrm{v} \\
\text { metillus. HFpEF: } \\
\text { failure. }\end{array}$ & $\begin{array}{l}\left.10^{6} / \mathrm{ml}\right) \text { fro } \\
\text { nts were in } \\
\text {. By ELISA, } \\
\text { Total Ang1 } \\
\text { les for Intra } \\
\text { ion), theref } \\
{ }^{t} p<0.05 \text { al } \\
\text { ailure with }\end{array}$ & $\begin{array}{l}\text { healthy c } \\
\text { bated at } 3 \\
\text { le quantifie } \\
\text { orrespond } \\
\text { ellular and } \\
\text { e are not ir } \\
{ }^{++} p<0.01 \\
\text { eserved ej }\end{array}$ & $\begin{array}{l}\text { trols }(\mathrm{HC}) \text {, } \\
\text { 'C for } 3 \mathrm{hou} \\
\text { Ang1 from } \\
\text { to the additi } \\
\text { ound to } \mathrm{NE} \\
\text { luded in the } \\
\text { s HC. HC: } \mathrm{h} \\
\text { tion fractio }\end{array}$ & $\begin{array}{l}\text { 2DM, stabl } \\
\text { s with diffe } \\
\text { unstimulate } \\
\text { on of Ang1 } \\
\text { 's are show } \\
\text { statistical } \\
\text { ealthy contr } \\
\text {. ADHF: ac }\end{array}$ & $\begin{array}{l}\text { HFpEF } \pm \text { T2 } \\
\text { ent agonists } \\
\text { neutrophils } \\
\text { leased, intra } \\
\text { but are bel } \\
\text { alyses. } 8 \mathrm{p}< \\
\text { T2DM: typ } \\
\text { e decomper }\end{array}$ & $\begin{array}{l}\text { M and } \\
\text { PBS control, } \\
\text { (TO) and } \\
\text { cellular and } \\
\text { w the LLOQ } \\
.05, \S \S p<0.01 \\
2 \text { diabetes } \\
\text { sated heart }\end{array}$ \\
\hline
\end{tabular}

\section{Calprotectin release, intracellular content and NETs binding in neutrophils}

We assessed the calprotectin (S100A8/S100A9) release, intracellular content and binding capacity to released NETs in isolated neutrophils from all 6 cohorts upon stimulation with PBS, LPS, PMA, and A23187 for 3 hours. The post-isolation calprotectin intracellular content (T0) in neutrophils from HC was $55.9 \pm 8.7 \mu \mathrm{g} / 5 \times 10^{6}$ neutrophils $/ \mathrm{mL}$, while a higher concentration (non-significant) was observed for all patient's cohorts (Table 3). 
Table 3

Calprotectin synthesis and release from neutrophils

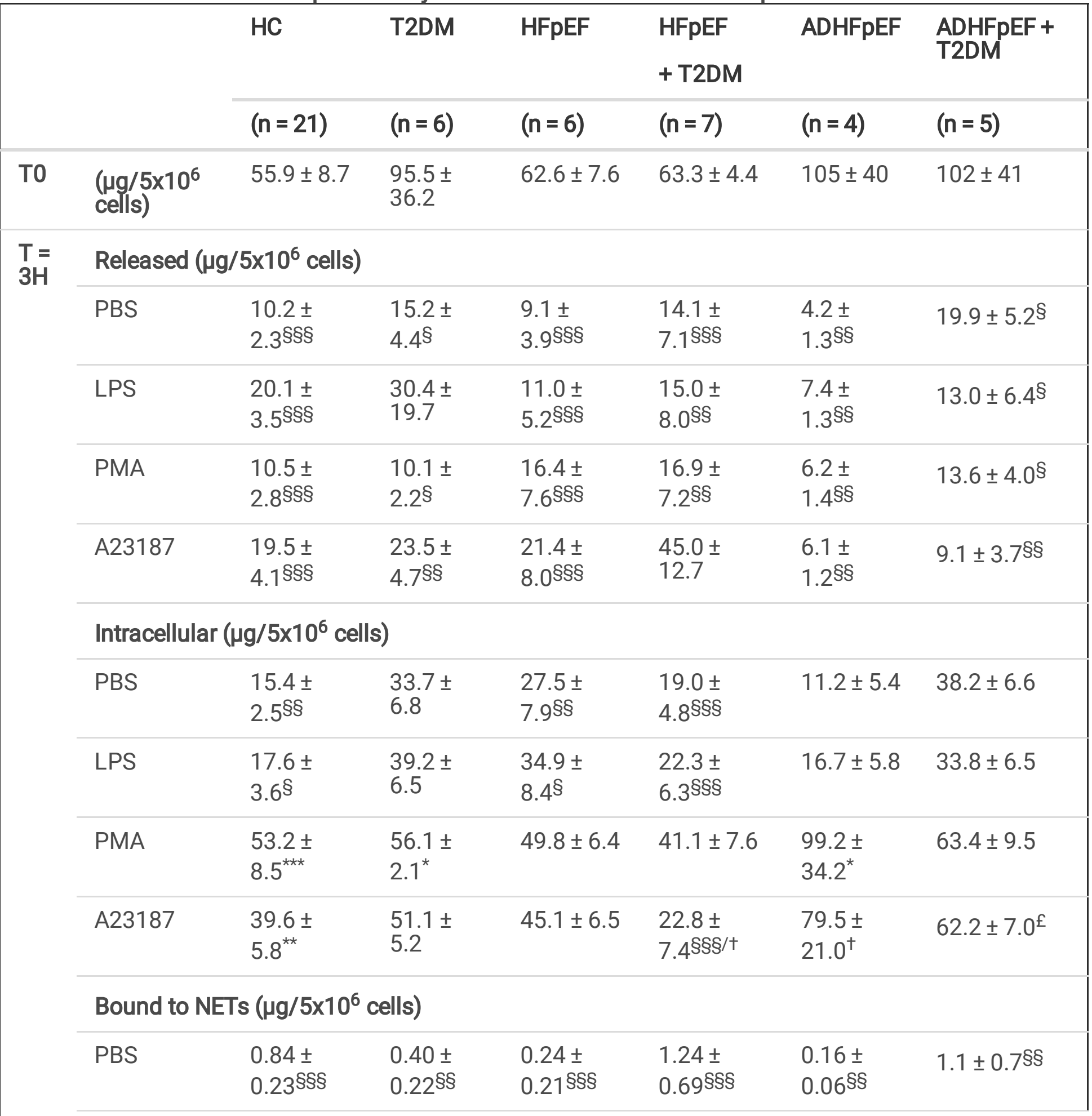

Isolated neutrophils $\left(5 \times 10^{6} / \mathrm{ml}\right)$ from healthy control $(\mathrm{HC})$ subjects, T2DM, stable HFpEF \pm T2DM and ADHFpEF \pm T2DM patients were incubated at $37^{\circ} \mathrm{C}$ for 3 hours with different agonists (PBS control, PMA, LPS and A23187). By ELISA, we quantified calprotectin from unstimulated neutrophils (T0) and stimulated neutrophils. Total calprotectin corresponds to the addition of calprotectin released,

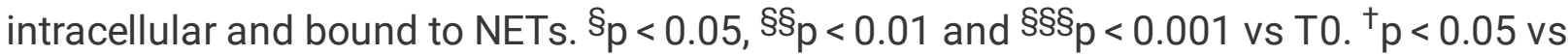
corresponding control w/o HF (HC/T2DM). ${ }^{\star} p<0.05$, ${ }^{* \star} p<0.01$ and ${ }^{* * *} p<0.001$ vs PBS. ${ }^{{ }^{*}} p<0.05$ vs HFpEF + T2DM 


\begin{tabular}{|c|c|c|c|c|c|c|}
\hline & $\mathrm{HC}$ & T2DM & HFpEF & $\begin{array}{l}\text { HFpEF } \\
+ \text { T2DM }\end{array}$ & ADHFpEF & $\begin{array}{l}\text { ADHFpEF + } \\
\text { T2DM }\end{array}$ \\
\hline & $(n=21)$ & $(n=6)$ & $(n=6)$ & $(n=7)$ & $(n=4)$ & $(n=5)$ \\
\hline LPS & $\begin{array}{l}0.41 \pm \\
0.18 \S \S \S\end{array}$ & $\begin{array}{l}0.25 \pm \\
0.16 \S \S\end{array}$ & $\begin{array}{l}0.04 \pm \\
0.02 \S \S \S\end{array}$ & $\begin{array}{l}0.81 \pm \\
0.63 \S \S \S\end{array}$ & $\begin{array}{l}0.23 \pm \\
0.13 \S \S\end{array}$ & $1.3 \pm 1.0 \S \S$ \\
\hline PMA & $\begin{array}{l}1.0 \pm \\
0.2^{\S \S \S}\end{array}$ & $\begin{array}{l}1.3 \pm \\
0.2^{\S \S}\end{array}$ & $\begin{array}{l}2.1 \pm \\
0.8 \S \S \S\end{array}$ & $\begin{array}{l}3.6 \pm \\
2.0 \S \S \S\end{array}$ & $\begin{array}{l}2.3 \pm \\
1.3 \S \S\end{array}$ & $2.3 \pm 0.9 \S \S$ \\
\hline A23187 & $\begin{array}{l}3.3 \pm \\
0.6 \S \S \S / * \star \star\end{array}$ & $\begin{array}{l}3.2 \pm \\
0.9 \S \S^{/ * *}\end{array}$ & $\begin{array}{l}3.3 \pm \\
1.6 \S \S \S\end{array}$ & $\begin{array}{l}2.3 \pm \\
1.2^{\S \S \S}\end{array}$ & $\begin{array}{l}1.9 \pm \\
0.9 \S \S\end{array}$ & $2.6 \pm 1.8 \S \S$ \\
\hline Total $(\mu \mathrm{g}$ & $0^{6}$ cells) & & & & & \\
\hline PBS & $\begin{array}{l}26.5 \pm \\
3.8 \S \S\end{array}$ & $\begin{array}{l}49.3 \pm \\
9.3\end{array}$ & $\begin{array}{l}36.8 \pm \\
11.2\end{array}$ & $34.4 \pm 8.7$ & $15.6 \pm 6.7$ & $59.2 \pm 11.2$ \\
\hline LPS & $38.1 \pm 6.0$ & $\begin{array}{l}69.9 \pm \\
19.2\end{array}$ & $\begin{array}{l}50.5 \pm \\
11.5\end{array}$ & $\begin{array}{l}38.1 \pm \\
14.5\end{array}$ & $24.3 \pm 6.3$ & $48.1 \pm 13.5$ \\
\hline PMA & $\begin{array}{l}64.7 \pm \\
9.0^{*}\end{array}$ & $\begin{array}{l}66.5 \pm \\
3.4\end{array}$ & $68.3 \pm 8.9$ & $\begin{array}{l}61.6 \pm \\
10.8\end{array}$ & $108 \pm 36^{*}$ & $79.3 \pm 13.1$ \\
\hline A23187 & $\begin{array}{l}62.4 \pm \\
9.4^{*}\end{array}$ & $\begin{array}{l}76.7 \pm \\
7.1\end{array}$ & $\begin{array}{l}69.9 \pm \\
14.8\end{array}$ & $\begin{array}{l}70.0 \pm \\
10.2\end{array}$ & $\begin{array}{l}87.5 \pm \\
22.2\end{array}$ & $74.0 \pm 6.2$ \\
\hline $\begin{array}{l}\text { Isolated neutroph } \\
\text { ADHFpEF } \pm \text { T2D } \\
\text { PMA, LPS and A2 } 2 \\
\text { stimulated neutrc } \\
\text { intracellular and } \\
\text { corresponding co } \\
\text { HFpEF + T2DM }\end{array}$ & $\begin{array}{l}\left.5 \times 10^{6} / \mathrm{ml}\right) \mathrm{f} \\
\text { tients were } \\
\text { 37). By ELIS, } \\
\text { ls. Total calp } \\
\text { nd to NETs. } \\
\text { l w/o HF (H }\end{array}$ & $\begin{array}{l}\text { m healthy } \\
\text { cubated a } \\
\text { we quanti } \\
\text { tectin col } \\
<0.05 \text {, §§ } \\
\text { T2DM). * }\end{array}$ & $\begin{array}{l}\text { ontrol }(\mathrm{HC}) \mathrm{sl} \\
7^{\circ} \mathrm{C} \text { for } 3 \text { hou } \\
\text { d calprotecti } \\
\text { ponds to th€ } \\
0.01 \text { and } \S \S \S \\
0.05,{ }^{\star \star} \mathrm{p}<0\end{array}$ & $\begin{array}{l}\text { jects, T2DN } \\
\text { s with differ } \\
\text { from unstin } \\
\text { addition of } \\
<0.001 \text { vs } \\
1 \text { and ***p }\end{array}$ & $\begin{array}{l}\text { stable HFpE } \\
\text { tt agonists ( } \\
\text { lated neutro } \\
\text { Iprotectin re } \\
{ }^{\dagger} p<0.05 \mathrm{v} \\
.001 \text { vs PBS }\end{array}$ & $\begin{array}{l} \pm \text { T2DM and } \\
\text { BS control, } \\
\text { hils (T0) and } \\
\text { eased, } \\
f_{\mathrm{p}}<0.05 \text { vs }\end{array}$ \\
\hline
\end{tabular}

In all 6 cohorts and independently from the agonist used, the calprotectin released was significantly lower than the initial quantity found in post-isolation neutrophils (T0). None of the agonists significantly increased the calprotectin release when compared to unstimulated neutrophils (PBS).

In all 6 cohorts and independently from the agonist used, the intracellular calprotectin was lower than the initial quantity found in post-isolation neutrophils (T0). PMA-stimulated neutrophils from HC, T2DM and ADHFpEF increased significantly (up to 8.8-fold; $99 \mathrm{vs} 11 \mu \mathrm{g} / \mathrm{mL}$ in ADHFpEF) the calprotectin intracellular content compared to PBS. A23187-stimulated neutrophils from HC significantly increased the intracellular calprotectin (2.6-fold; $39.6 \mathrm{vs} 15.5 \mu \mathrm{g} / \mathrm{mL}$ ), HFpEF + T2DM had a significantly lower concentration of intracellular calprotectin ( $55 \%$ decrease; $22.8 \mathrm{vs} 51.1 \mu \mathrm{g} / \mathrm{mL}$ ) compared to T2DM patients, whereas in ADHFpEF patients it increased significantly (2.0-fold; $79.5 \mathrm{vs} 39.6 \mu \mathrm{g} / \mathrm{mL}$ ) compared 
to HC. Finally, we observed a significant increase (2.7-fold; 62.3 vs $22.8 \mu \mathrm{g} / \mathrm{mL})$ in the calprotectin neutrophil content from ADHFpEF + T2DM compared to HFpEF + T2DM (Table 3).

In all 6 cohorts and independently from the agonist used, calprotectin was detected on NETs but was significantly lower than in the intracellular fraction post-isolation (TO). A treatment with PMA increased the calprotectin NETs binding in all cohorts by up to 15 -fold in ADHFpEF ( $2.30 \mathrm{vs} 0.15 \mu \mathrm{g} / \mathrm{mL}$ ), while the A23187 stimulation provided a significant increase in HC and T2DM (up to 8-fold; $3.20 \mathrm{vs} 0.40 \mu \mathrm{g} / \mathrm{mL}$ in T2DM) compared to PBS.

The total calprotectin (released + intracellular + bound to NETs) following the 3-hour neutrophil incubation with PBS or LPS was lower than post-isolation (T0) in all 6 cohorts, but only significant for PBS in HC ( $53 \%$ decrease; 26.5 vs $55.9 \mu \mathrm{g} / \mathrm{mL}$ ). When stimulated with PMA for 3 hours, the total calprotectin remained unchanged compared to T0, while being significantly higher in $\mathrm{HC}$ (2.4-fold; 64.7 vs 26.5 $\mu \mathrm{g} / \mathrm{mL}$ ) and in ADHFpEF (6.9-fold; $108 \mathrm{vs} 15.6 \mu \mathrm{g} / \mathrm{mL}$ ) when compared to PBS (Table 3).

\section{Imaging of Ang 1 and calprotectin localization in human neutrophils}

Based on our aforementioned data, we sought to visualize whether Ang1 and calprotectin behave differently in regard to their binding to NETs, using confocal microscopy. Neutrophils isolated from HC were treated with PBS, LPS, PMA, and A23187 for 3 hours, followed by a series of incubations with antibodies detecting either Ang1 (Fig. 2) or calprotectin (Fig. 3).

First, we observed that in unstimulated neutrophils (PBS), there is no or marginal detection of Sytox orange due to a very low percentage of permeabilized cell membrane and absence of intracellular DNA exposure. Treatment with LPS induced a small synthesis and release of NETs (green), whereas a treatment with PMA and A23187 induced a marked increase of NETs synthesis and release (Figs. 2 and 3; Sytox Orange column). For the detection of Ang1 and calprotectin proteins, we observed a similar pattern, namely a marginal intracellular detection of both proteins under PBS and LPS treatments, whereas under PMA and A23187 stimulation, cell permeabilization associated to NETosis allowed the specific binding of Ang1 and calprotectin antibodies intracellularly (Figs. 2 and 3; Antibody and merged columns). In addition to the detection of Ang1, calprotectin and NETs within the neutrophils, we observed that Ang1 as opposed to calprotectin does not seem to be bound to extracellular NETs (Fig. 4).

\section{Discussion}

In the present study, we report that neutrophils from patients diagnosed with T2DM alone, HFpEF \pm T2DM or ADHFpEF w/o T2DM present a slight non-significant NETs increase, whereas ADHFpEF + T2DM patients have a higher significant NETs release after a 3-hour incubation with PBS (control vehicle) or LPS (a weak NETs inducer), compared to HC. In addition, ADHFpEF + T2DM patients present a lower Ang1 release from their neutrophils, while having a higher capacity to promote calprotectin release under basal (PBS) condition. Finally, in all 6 cohorts and independently from the agonist used, we observed that, while 
calprotectin was found to bind to the NETs web-like structures, Ang1 did not interact with NETs, suggesting that NETs are selective transporters of proteins. These data suggest that patients with symptomatic HF-pEF exhibit significant neutrophil activation and NETs release. The magnitude of NETs release is significantly increased in patients with ADHF.

\section{NETs release from human neutrophils}

It has been demonstrated that neutrophils are not just first responders to acute infections but also active contributors to low-grade chronic inflammation (39), which can be explained, in part, by their capacity to release NETs (40). NETs can be considered as a risk factor of future cardiovascular events because of their role in atherosclerosis, inflammation, and vascular thrombosis $(2,10,41,42)$. There has been little precious data on the release of NETS in the context of heart failure. More recently, we and other groups reported elevated levels of circulating NETs in T2DM patients and an increase in their neutrophil capacity in vitro to release NETs $(15,43,44)$. Furthermore, we observed an increase in circulating NETs and corresponding release in HF patients, the latter reaching a maximum in HF + T2DM (15). The results from this study confirm that NETs release is significantly increased in clinical HF and more so in patients with HF and T2DM. In this study, we used inflammatory mediators, such as LPS, PMA and A23187, targeting different signalling pathways to induce NETosis by human neutrophils (45-49). LPS, a component of gram-negative bacteria, induces NADPH oxidase (NOX)-dependent NETs formation mediated by c-Jun Nterminal kinases (JNK). LPS binds to Toll-like receptor (TLR4) on the surface of neutrophils, activating the production of reactive oxygen species (ROS) and NOX, inducing lytic NETs formation in a concentrationand NOX-dependent manner (47). Other groups have shown that LPS can also induce vital NETs formation via a NOX-independent pathway $(48,49)$. Many groups have shown that PMA-induced NETs formation requires ROS production by the NOX complex (50) and in some cases, the hypercitrullination of histone 3 (H3) by the peptidylarginine deiminase 4 (PAD4) (51, 52). A23187, a calcium ionophore, induces NETs formation in a NOX-independent but PAD4-dependent manner. This type of NETs formation is induced mainly through calcium influx and ROS production (46).

In the present study, we sought to determine the ability of these inflammatory mediators to induce NETs formation by neutrophils from HC, T2DM alone, stable HFpEF \pm T2DM and ADHFpEF \pm T2DM patients. Our study revealed significantly higher basal (PBS) and LPS-induced NETs release only in patients with ADHFpEF + T2DM, as compared with HC. In addition, released NETs were increased at basal level and significantly following LPS stimulation in ADHFpEF + T2DM patients vs ADHFpEF w/o T2DM, suggesting that T2DM contributes to increase the inflammatory state in ADHFpEF patients. We did observe an increase, although non-significant, in basal or LPS-induced NETs release in T2DM alone or stable HFpEF \pm T2DM patients, and this might be an indicator that the management of their low-grade inflammatory condition by the current chronic therapies is not fully capable to revert the inflammatory state associated to NETosis.

The increase in NETs release seen in ADHFpEF + T2DM patients support the concept that these patients are in a state of acute thrombo-inflammation. Such status may lead to a pro-thrombotic state wherein 
blood vessel obstruction could result in inadequate blood supply to the heart and/or other organs. Therefore, NETs and T2DM can jointly contribute to the progression and severity of HF, leading ultimately to the ADHF condition.

\section{Angiopoietin 1 release and NETs binding}

In this study, we wanted to determine if the release of Ang1 was comparable to calprotectin, since both proteins are found in the cytosol of neutrophils. We previously demonstrated that in healthy controls, Ang1 is found in the cytosol of neutrophils and can be released upon stimulation with different stimuli (35). Ang1 is an important inflammatory marker for the stabilization and maturation of blood vessels through Tie2 receptor $(34,53)$. Studies have shown that a decrease of circulating Ang1 levels in patients with acute myocardial infarction and major cardiovascular conditions such as arrhythmia, valvular heart disease, HF and cardiogenic shock, could be potentially associated with the magnitude of endothelial dysfunction $(37,54)$. In our study, we also observed a lower concentration of intracellular Ang1 in postisolated (T0) neutrophils in all patients' cohorts. These neutrophils increase their Ang1 synthesis over a 3hour incubation time period, yet, their corresponding Ang1 concentrations never reached the levels observed in HC. Interestingly, the lowest Ang1 concentration post-incubation was observed in both ADHFpEF + T2DM and stable HFpEF + T2DM suggesting that T2DM co-morbidity is negatively impacting the capacity of neutrophils from HF patients to synthesize Ang1. This could contribute to inadequate stabilization of blood vessels, endothelial dysfunction and disease progression.

Since neither calprotectin nor Ang1 are stored in neutrophil granules or vesicles $(35,55,56)$, and that calprotectin binds to NETs when released, we wanted to assess if Ang1 exocytosis was also NETsdependent. Herein, we observed that Ang1 was not detected on the surface of extracellular NETs, either by ELISA or using confocal microscopy, suggesting that its secretion is NETs-independent in all 6 cohorts studied. This could be explained by the fact that Ang1 is not an essential bactericidal protein, like MPO, NE or calprotectin, all found on NETs. Moreover, Ang1 has been shown to bind either to Tie2 receptor and selected integrins, both expressed on cell membrane surface of neutrophils $(7,57,58)$. In addition, the low concentration of Ang1 ( 100-200 pg/5x106 neutrophils) being released as compared to calprotectin ( 5-20 mg/5x $10^{6}$ neutrophils) could explain their membrane proximity, as observed by confocal microscopy, suggesting an autocrine agonistic activity upon its release from the neutrophils.

\section{Calprotectin release and NETs binding}

Calprotectin (S100A8/A9) is largely expressed in the cytoplasm of neutrophils and is mainly released in an infectious setting. Moreover, calprotectin can bind to NETs (3) and exerts its main function, namely anti-microbial, in combination with other NETs-bound proteins such as MPO and NE, while NETs are keeping pathogens trapped, thus leading to increased efficiency in pathogens removal.

Calprotectin has also recently been shown to be involved in cardiovascular diseases, following its release by inflammatory mediators $(59,60)$. Previous studies reported a higher serum or plasma calprotectin level in patients with chronic HF and was associated with other inflammatory markers such as C-reaction 
protein (CRP), interleukin IL-6, IL-8 and TNF-a $(31,61,62)$. In the present study, we observed an increase of intracellular calprotectin in neutrophils post-isolation (T0) from T2DM and ADHFpEF \pm T2DM patients as compared to $\mathrm{HC}$, whereas in stable HFpEF \pm T2DM the calprotectin initial content remained unchanged. However, there was no additional calprotectin synthesis after $3 \mathrm{~h}$ of stimulation in all 6 cohorts and independently from the agonists used. The increase of endogenous calprotectin observed in freshly isolated neutrophils from these patients could indicate an increased inflammatory status, thereby contributing to the progression of heart failure.

After $3 \mathrm{~h}$ of stimulation and in absence of agonist stimulation (PBS), we observed in all 6 cohorts that the level of calprotectin was reduced by 40 to $85 \%$ compared to corresponding T0 values. In addition, even after stimulation with LPS, PMA or A23187 agonists, the levels of calprotectin remained either below or comparable to T0 values. Thus, we hypothesized that this decrease could be associated to calprotectin degradation by the proteasome. However, when using the proteasome inhibitor (MG132; $10 \mu \mathrm{M})(63)$, it did not prevent the reduction of intracellular calprotectin concentration, neither the total concentration of calprotectin (data not shown). One possibility might be that oxidative post-translational modifications of calprotectin makes it a target for proteasome-independent proteolysis (64).

As previously described $(1,3)$, we observed that a fraction (up to $5.3 \%$ ) of the total calprotectin detected at $3 \mathrm{~h}$ post-incubation was bound to NETs as observed by ELISA and confocal microscopy (Table 3 and Fig. 3). Only NETs produced by PMA and A23187 bound more calprotectin, since those two agonists induced a higher NETs release in all cohorts (Fig. 1). Interestingly, in HC and T2DM patients, A23187 induced the release of mostly web-like NETs as seen in Fig. 3, and this conformation bound more calprotectin than the PMA-mediated NETs synthesis, localized mostly near the cells. This could be explained by the fact that NETs web-like structures are observed in microbial trapping, thus supporting the calprotectin antimicrobial role $(1,65,66)$.

\section{Study limitations}

This study consisted of a small sample size of patients with various duration, etiology and severity of HF. Clinically relevant information such as the duration of diabetes, glycemic control, and the concomitant presence of atherosclerotic heart disease were not readily available. In vitro neutrophil experiments were limited to stimulation with few agonists and to the measure of Ang1 and calprotectin. Future studies warrant the inclusion of other cytokines and higher number of patients.

\section{Conclusions}

In our study, NETs released by isolated neutrophils upon stimulation with selected agonists were significantly increased in ADHFpEF + T2DM when compared to healthy control volunteers. In addition, the release of Ang1 is independent from NETosis and not affected by diabetes or heart failure conditions. On the other side and as expected, calprotectin does bind to NETs, with the constitutive basal levels of calprotectin tending to increase in neutrophils from T2DM and ADHFpEF \pm T2DM patients. Since neutrophils from ADHF + T2DM have a higher capacity to release NETs under basal condition, their 
capacity to bind calprotectin might further exacerbate NETs-mediated pro-inflammatory activities in these patients.

\section{Methods}

\section{Population}

This was a prospective non-randomized non-interventional study including stable HFpEF or ADHFpEF, with or without T2DM, compared with T2DM patients and HC without any heart pathology. Six different cohorts were recruited at the Montreal Heart Institute (MHI): 1) HC ( $=34), 2)$ T2DM $(n=8), 3)$ stable $\operatorname{HFpEF}(n=5), 4)$ stable HFpEF + T2DM $(n=7), 5) \operatorname{ADHFpEF}(n=7)$ and 6) ADHFpEF + T2D $(n=6)$. Blood collection from all participants was performed at the MHI. The study has been approved by the MHI's Research Ethics Committee and performed with the accordance of the Declaration of Helsinki. Informed consent was obtained from all subjects prior to the study (Montreal, QC, Canada; ethics No. ICM\#01-069 and No. ICM \#12-1374).

\section{Selection criteria of healthy control volunteers and patients}

Healthy controls $(\mathrm{HC})$ recruited in this study were enrolled assuming they had no significant medical conditions and were not treated by any anti-inflammatory medication for at least 14 days before blood collection. T2DM patients with no symptoms or signs of HF were recruited from the Clinique d'Endocrinologie de Montréal. HFpEF and ADHFpEF patients with NYHA classification I to IV symptoms were recruited from the $\mathrm{MHI}$ heart failure clinic and from the emergency room (ER) or HF care units respectively. These patients were classified as HFpEF if their LVEF was $\geq 50 \%$ (67-69), as documented by contrast ventriculography, magnetic resonance imaging, radionuclide ventriculography or echocardiography assessed within the previous 12 months and if no significant cardiac events occurred since the assessment of LVEF (68). These patients were optimally treated on stable doses of A-II modulating agents, beta-blocker, and mineralo-corticoid antagonist agents unless not tolerated or contraindicated. In addition to the previous inclusion criteria outlined above, patients with HF + T2DM required an $\mathrm{HbA} 1 \mathrm{c}<10 \%$ and good glycemic control by any available hypoglycaemic medications and treated with secondary preventive medication as per current guidelines. The most significant exclusion criteria included the presence of severe chronic pulmonary disease, chronic active inflammatory disease, severe renal failure (creatinine $>250 \mu \mathrm{mol} / \mathrm{L}$ ), liver damage (transaminases $\geq 3$-fold upper normal values) and ongoing malignancy. Other exclusion criteria included recent myocardial infarction, stroke, or cardiac surgery ( $<3$ months). All participants having ongoing and/or recent infection within 2 weeks prior to the study were excluded from this study.

\section{Study protocol - plasma, serum and neutrophil collection}


Venous blood from all participants was collected in $30 \mathrm{~mL}$ syringes (containing $5 \mathrm{~mL}$ acid citrate dextrose for $25 \mathrm{~mL}$ whole blood). Neutrophils were isolated using the Ficoll-Paque gradient method, as previously described $(70,71)$. Upon isolation, neutrophils were resuspended in phenol-free RPMI-1640 medium (Cambrex Bio Science, Walkersville, MD) supplemented with 1) 25 mM HEPES (N-2hydroxyethylpiperazine-N'-2-ethanesulfonic acid) (Sigma-Aldrich, Oakville, ON, Canada), 2) 1\% penicillin/streptomycin/ Glutamax (VWR Intl., Montreal, QC, Canada), 3) $1 \mathrm{mM} \mathrm{CaCl} 2$ (BDH Chemicals, Toronto, ON, Canada) and 4) 5\% FBS (Fetal Bovine serum; VWR) (termed complete RPMI). Contamination by PMBCs was less than $0.1 \%$ as determined by morphological analysis and flow cytometry. Cell viability of neutrophils were greater than $98 \%$, as assessed by Trypan blue dye exclusion assay.

\section{NETs production and quantification by fluorometric assays}

Isolated neutrophils $\left(5 \times 10^{6} / \mathrm{ml}\right)$ were added to 12 -well plates and incubated in complete RPMI at $37^{\circ} \mathrm{C}$ for 3 hours with either PBS-control buffer, LPS (100 nM; Escherichia coli 0111:B4; Sigma), PMA (25 nM; Calbiochem, La Jolla, CA, USA) or A23187 ( $5 \mu \mathrm{M}$; Calbiochem). Neutrophils were carefully washed two times with PBS $1 \mathrm{X}$, and nuclease S7 (Sigma) was added for $15 \mathrm{~min}$ at $37^{\circ} \mathrm{C}, 5 \% \mathrm{CO}_{2}$ to release NETs bound to the external surface of neutrophils with no or minor loss of NET structure and activity. The reaction was stopped with $10 \mathrm{mM}$ EDTA (Sigma), and the supernatant was centrifuged at $300 \mathrm{~g}$ for 5 min to remove cell debris. NETs were quantified using Quant-IT PicoGreen dsDNA Assay Kits (catalog no. P7589; Invitrogen, Eugene, OR).

\section{Localisation and release of Ang1 and calprotectin by ELISA}

The intracellular Ang1 and calprotectin concentrations in neutrophils $\left(5 \times 10^{6}\right.$ cells $\left./ \mathrm{mL}\right)$ were determined either immediately after isolation ( $T=0$ ), or upon agonists (PBS, LPS, PMA or A23187) stimulation in 6well plates for 3 hours at $37^{\circ} \mathrm{C}, 5 \% \mathrm{CO}_{2}$. The supernatants were collected and centrifuged at $300 \mathrm{~g}$ for 5 min to remove cell debris. Neutrophils were then carefully washed two times with PBS, and DNase I (Sigma) was added for $30 \mathrm{~min}$ at $37^{\circ} \mathrm{C}, 5 \% \mathrm{CO}_{2}$. The supernatant was collected in $10 \mathrm{mM}$ EDTA to stop the reaction and centrifuged at $300 \mathrm{~g}$ for $5 \mathrm{~min}$ to remove cell debris. A solution containing complete $\mathrm{RPMI}+1 \%$ Triton was added to the remaining adhered neutrophils which were then removed using a cell lifter, homogenized by vortex mixing and centrifuged at $18000 \mathrm{~g}$ for $10 \mathrm{~min}$. The cell membranes pellet was discarded and the supernatant was used for intracellular content measures. All samples were stored at $-80^{\circ} \mathrm{C}$ for further Ang1 quantification using ELISA DuoSet kits (R\&D System). Since the concentration of Ang1 was too low for direct detection by ELISA, all samples were concentrated 5 -fold by evaporating all the water $(1 \mathrm{~mL})$ from the samples using a SpeedVac and resuspending the dry fraction in $200 \mu \mathrm{L}$ of complete RPMI prior to their quantification. 


\section{Localisation of calprotectin and Ang1 on NETs by confocal microscopy}

Neutrophils $\left(1 \times 10^{6} / \mathrm{mL}\right)$ in complete RPMI were incubated in $35 \mathrm{~mm}$ petri dishes with $14 \mathrm{~mm}$ microwell insert (MatTek; \#P35G-1.0-14-C Ashland, MA, USA) for 3 hours at $37^{\circ} \mathrm{C}, 5 \% \mathrm{CO}_{2}$ with different agonists (PBS, PMA, LPS and A23187). After carefully removing the supernatant, 1\% BSA (Bovine serum albumin) was added for $30 \mathrm{~min}$ at $37^{\circ} \mathrm{C}, 5 \% \mathrm{CO}_{2}$. Primary antibodies (rabbit anti-human Ang1 (1:100) and mouse anti-human S100A8/A9 (1:20)), IgG isotype control (rabbit or mouse (both 1:200)) were added directly for 30 min at $37^{\circ} \mathrm{C}, 5 \% \mathrm{CO}_{2}$, followed by a gentle wash with HBSS $1 \mathrm{X}$. Subsequently, secondary antibodies (Alexa Fluor 488 conjugated goat anti-rabbit and Alexa Fluor 488 conjugated rabbit anti-mouse (both 0.5 $\mu \mathrm{g} / \mathrm{mL}$ )) were added and incubated for $30 \mathrm{~min}$ at $37^{\circ} \mathrm{C}, 5 \% \mathrm{CO}_{2}$, followed by two washes with HBSS $1 \mathrm{X}$. A fluorescent nucleic acid stain detecting double-stranded DNA in membrane disrupted cells (NETs) (Sytox Orange; 1:5000, Life Technologies), and WGA (Wheat germ agglutinin; $1 \mu \mathrm{g} / \mathrm{mL}$, ThermoFisher) to detect cell membrane were added. Images (Z stack) were obtained by confocal microscopy (LSM 710, Carl Zeiss).

\section{Statistical Analysis}

The data are presented as mean \pm SEM. All statistical analyses were performed using GraphPad Prism 5.0. Groups were compared by analysis of variance (ANOVA), followed by Dunnett's post-test for multiple comparisons. The results were considered significant if $p$ values were $<0.05$.

\section{Declarations}

\section{Ethics approval and consent to participate}

The study has been approved by the MHI's Research Ethics Committee and performed with the accordance of the Declaration of Helsinki. Informed consent was obtained from all subjects prior to the study (Montreal, QC, Canada; ethics No. ICM\#01-069 and No. ICM \#12-1374).

\section{Consent for publication}

Not applicable

\section{Availability of data and materials}

Not applicable

\section{Competing interests}


The authors declare that they have no competing interests.

\section{Funding}

This work was supported by grants from the Canadian Institutes of Health Research (MOP-97943 to MGS), Fondation de l'Institut de Cardiologie de Montréal (FICM) (to MGS). BV was recipient of a fellowship from FRQS, MW is the recipient of the Carolyn and Richard Renaud Endowed Research Chair in Heart Failure of the Montreal Heart Institute.

\section{Authors' contributions}

EC recruited healthy control volunteers, performed the experiments and data analyses and was a major contributor in writing the manuscript. BLD participated to the recruitment of patients and analyzed clinical data. SB participated to patient's recruitment and analyzed clinical data. PEN supervised EC and revised the manuscript. LV is the confocal microscopy platform operator, providing the image capture and helping with the analyses. AR helped with the diabetic patients' recruitment and with the data interpretation regarding those patients. MW is the co-PI of this study and the co-supervisor of EC and helped with the recruitment of heart failure patients and with the manuscript writing. MGS is the PI of this study and the principal supervisor of EC and helped with the writing of the manuscript. All authors read and approved the final manuscript.

\section{Acknowledgements}

Not applicable

\section{References}

1. Brinkmann V, Reichard U, Goosmann C, Fauler B, Uhlemann Y, Weiss DS, et al. Neutrophil extracellular traps kill bacteria. Science. 2004;303(5663):1532-5.

2. Mitsios A, Arampatzioglou A, Arelaki S, Mitroulis I, Ritis K. NETopathies? Unraveling the Dark Side of Old Diseases through Neutrophils. Front Immunol. 2016;7:678.

3. Urban CF, Ermert D, Schmid M, Abu-Abed U, Goosmann C, Nacken W, et al. Neutrophil extracellular traps contain calprotectin, a cytosolic protein complex involved in host defense against Candida albicans. PLoS Pathog. 2009;5(10):e1000639.

4. McCormick A, Heesemann L, Wagener J, Marcos V, Hartl D, Loeffler J, et al. NETs formed by human neutrophils inhibit growth of the pathogenic mold Aspergillus fumigatus. Microbes Infect. 2010;12(12-13):928-36.

5. Brill A, Fuchs TA, Savchenko AS, Thomas GM, Martinod K, De Meyer SF, et al. Neutrophil extracellular traps promote deep vein thrombosis in mice. J Thromb Haemost. 2012;10(1):136-44. 
6. von Bruhl ML, Stark K, Steinhart A, Chandraratne S, Konrad I, Lorenz M, et al. Monocytes, neutrophils, and platelets cooperate to initiate and propagate venous thrombosis in mice in vivo. J Exp Med. 2012;209(4):819-35.

7. Law SM, Gray RD. Neutrophil extracellular traps and the dysfunctional innate immune response of cystic fibrosis lung disease: a review. J Inflamm (Lond). 2017;14:29.

8. Yoo DG, Floyd M, Winn M, Moskowitz SM, Rada B. NET formation induced by Pseudomonas aeruginosa cystic fibrosis isolates measured as release of myeloperoxidase-DNA and neutrophil elastase-DNA complexes. Immunol Lett. 2014;160(2):186-94.

9. Pinegin B, Vorobjeva N, Pinegin V. Neutrophil extracellular traps and their role in the development of chronic inflammation and autoimmunity. Autoimmun Rev. 2015;14(7):633-40.

10. Doring Y, Soehnlein O, Weber C. Neutrophil Extracellular Traps in Atherosclerosis and Atherothrombosis. Circ Res. 2017;120(4):736-43.

11. Dwyer M, Shan Q, D'Ortona S, Maurer R, Mitchell R, Olesen H, et al. Cystic fibrosis sputum DNA has NETosis characteristics and neutrophil extracellular trap release is regulated by macrophage migration-inhibitory factor. J Innate Immun. 2014;6(6):765-79.

12. Papayannopoulos V. Neutrophil extracellular traps in immunity and disease. Nat Rev Immunol. 2018;18(2):134-47.

13. Menegazzo L, Ciciliot S, Poncina N, Mazzucato M, Persano M, Bonora B, et al. NETosis is induced by high glucose and associated with type 2 diabetes. Acta Diabetol. 2015;52(3):497-503.

14. Wong SL, Demers M, Martinod K, Gallant M, Wang Y, Goldfine AB, et al. Diabetes primes neutrophils to undergo NETosis, which impairs wound healing. Nat Med. 2015;21(7):815-9.

15. Vulesevic B, Lavoie SS, Neagoe PE, Dumas E, Rakel A, White M, et al. CRP Induces NETosis in Heart Failure Patients with or without Diabetes. Immunohorizons. 2019;3(8):378-88.

16. Pathophysiology and management of heart failure. Clinical Pharmacist. 2018.

17. Sorop O, Heinonen I, van Kranenburg M, van de Wouw J, de Beer VJ, Nguyen ITN, et al. Multiple common comorbidities produce left ventricular diastolic dysfunction associated with coronary microvascular dysfunction, oxidative stress, and myocardial stiffening. Cardiovasc Res. 2018;114(7):954-64.

18. Paulus WJ, Tschope C. A novel paradigm for heart failure with preserved ejection fraction: comorbidities drive myocardial dysfunction and remodeling through coronary microvascular endothelial inflammation. J Am Coll Cardiol. 2013;62(4):263-71.

19. Cohen-Solal A, Laribi S, Ishihara S, Vergaro G, Baudet M, Logeart D, et al. Prognostic markers of acute decompensated heart failure: the emerging roles of cardiac biomarkers and prognostic scores. Arch Cardiovasc Dis. 2015;108(1):64-74.

20. Bloom MW, Greenberg B, Jaarsma T, Januzzi JL, Lam CSP, Maggioni AP, et al. Heart failure with reduced ejection fraction. Nat Rev Dis Primers. 2017;3:17058. 
21. Chandra A, Vaduganathan M, Lewis EF, Claggett BL, Rizkala AR, Wang W, et al. Health-Related Quality of Life in Heart Failure With Preserved Ejection Fraction: The PARAGON-HF Trial. JACC Heart Fail. 2019;7(10):862-74.

22. Solomon SD, McMurray JJV, Anand IS, Ge J, Lam CSP, Maggioni AP, et al. Angiotensin-Neprilysin Inhibition in Heart Failure with Preserved Ejection Fraction. N Engl J Med. 2019;381(17):1609-20.

23. Joseph SM, Cedars AM, Ewald GA, Geltman EM, Mann DL. Acute decompensated heart failure: contemporary medical management. Tex Heart Inst J. 2009;36(6):510-20.

24. Raj L, Maidman SD, Adhyaru BB. Inpatient management of acute decompensated heart failure. Postgrad Med J. 2020;96(1131):33-42.

25. Wang S, Song R, Wang Z, Jing Z, Wang S, Ma J. S100A8/A9 in Inflammation. Front Immunol. 2018;9:1298.

26. Fagerhol MK. Nomenclature for proteins: is calprotectin a proper name for the elusive myelomonocytic protein? Clin Mol Pathol. 1996;49(2):M74-9.

27. Ryckman C, Vandal K, Rouleau P, Talbot M, Tessier PA. Proinflammatory activities of S100: proteins S100A8, S100A9, and S100A8/A9 induce neutrophil chemotaxis and adhesion. J Immunol. 2003;170(6):3233-42.

28. Foell D, Wittkowski H, Vogl T, Roth J. S100 proteins expressed in phagocytes: a novel group of damage-associated molecular pattern molecules. J Leukoc Biol. 2007;81(1):28-37.

29. Foell D, Frosch M, Sorg C, Roth J. Phagocyte-specific calcium-binding S100 proteins as clinical laboratory markers of inflammation. Clin Chim Acta. 2004;344(1-2):37-51.

30. Go AS, Mozaffarian D, Roger VL, Benjamin EJ, Berry JD, Blaha MJ, et al. Heart disease and stroke statistics-2014 update: a report from the American Heart Association. Circulation. 2014;129(3):e28e292.

31. Bruhn LV, Lauridsen KG, Schmidt AS, Rickers H, Bach LF, Lofgren B, et al. Elevated calprotectin in patients with atrial fibrillation with and without heart failure. Scand J Clin Lab Invest. 2017;77(3):210-5.

32. Adamis AP, Berman AJ. Chapter 70 - Inhibition of angiogenesis. In: Levin LA, Albert DM, editors. Ocular Disease. Edinburgh: W.B. Saunders; 2010. p. 544-53.

33. Li J-J, Huang Y-Q, Basch R, Karpatkin S. Thrombin Induces the Release of Angiopoietin-1 from Platelets. Thrombosis and haemostasis. 2001;85:204-6.

34. Davis S, Aldrich TH, Jones PF, Acheson A, Compton DL, Jain V, et al. Isolation of angiopoietin-1, a ligand for the TIE2 receptor, by secretion-trap expression cloning. Cell. 1996;87(7):1161-9.

35. Neagoe PE, Brkovic A, Hajjar F, Sirois MG. Expression and release of angiopoietin-1 from human neutrophils: intracellular mechanisms. Growth Factors. 2009;27(6):335-44.

36. Azzi S, Gavard J. [Blood vessels in cancer: can't stop whispering]. Med Sci (Paris). 2014;30(4):40814. 
37. Liu KL, Lin SM, Chang CH, Chen YC, Chu PH. Plasma angiopoietin-1 level, left ventricular ejection fraction, and multivessel disease predict development of 1-year major adverse cardiovascular events in patients with acute ST elevation myocardial infarction - a pilot study. Int J Cardiol. 2015;182:15560.

38. Link A, Poss J, Rbah R, Barth C, Feth L, Selejan S, et al. Circulating angiopoietins and cardiovascular mortality in cardiogenic shock. Eur Heart J. 2013;34(22):1651-62.

39. Caielli S, Banchereau J, Pascual V. Neutrophils come of age in chronic inflammation. Curr Opin Immunol. 2012;24(6):671-7.

40. Perez-Sanchez C, Ruiz-Limon P, Aguirre MA, Jimenez-Gomez Y, Arias-de la Rosa I, Abalos-Aguilera $\mathrm{MC}$, et al. Diagnostic potential of NETosis-derived products for disease activity, atherosclerosis and therapeutic effectiveness in Rheumatoid Arthritis patients. J Autoimmun. 2017;82:31-40.

41. Mozzini C, Garbin U, Fratta Pasini AM, Cominacini L. An exploratory look at NETosis in atherosclerosis. Intern Emerg Med. 2017;12(1):13-22.

42. Jorch SK, Kubes P. An emerging role for neutrophil extracellular traps in noninfectious disease. Nat Med. 2017;23(3):279-87.

43. Wong SL, Demers M, Martinod K, Gallant M, Wang Y, Goldfine AB, et al. Diabetes primes neutrophils to undergo NETosis, which impairs wound healing. Nature Medicine. 2015;21(7):815-9.

44. Menegazzo L, Ciciliot S, Poncina N, Mazzucato M, Persano M, Bonora B, et al. NETosis is induced by high glucose and associated with type 2 diabetes. Acta Diabetologica. 2014;52(3):497-503.

45. Takei H, Araki A, Watanabe H, Ichinose A, Sendo F. Rapid killing of human neutrophils by the potent activator phorbol 12-myristate 13-acetate (PMA) accompanied by changes different from typical apoptosis or necrosis. J Leukoc Biol. 1996;59(2):229-40.

46. Parker H, Dragunow M, Hampton MB, Kettle AJ, Winterbourn CC. Requirements for NADPH oxidase and myeloperoxidase in neutrophil extracellular trap formation differ depending on the stimulus. $J$ Leukoc Biol. 2012;92(4):841-9.

47. Khan MA, Farahvash A, Douda DN, Licht JC, Grasemann H, Sweezey N, et al. JNK Activation Turns on LPS- and Gram-Negative Bacteria-Induced NADPH Oxidase-Dependent Suicidal NETosis. Sci Rep. 2017;7(1):3409.

48. Yipp BG, Petri B, Salina D, Jenne CN, Scott BN, Zbytnuik LD, et al. Infection-induced NETosis is a dynamic process involving neutrophil multitasking in vivo. Nat Med. 2012;18(9):1386-93.

49. Yipp BG, Kubes P. NETosis: how vital is it? Blood. 2013;122(16):2784-94.

50. Papayannopoulos V, Metzler KD, Hakkim A, Zychlinsky A. Neutrophil elastase and myeloperoxidase regulate the formation of neutrophil extracellular traps. J Cell Biol. 2010;191(3):677-91.

51. Li P, Li M, Lindberg MR, Kennett MJ, Xiong N, Wang Y. PAD4 is essential for antibacterial innate immunity mediated by neutrophil extracellular traps. J Exp Med. 2010;207(9):1853-62.

52. Neeli I, Radic M. Opposition between PKC isoforms regulates histone deimination and neutrophil extracellular chromatin release. Front Immunol. 2013;4:38. 
53. Joussen AM, Poulaki V, Tsujikawa A, Qin W, Qaum T, Xu Q, et al. Suppression of diabetic retinopathy with angiopoietin-1. Am J Pathol. 2002;160(5):1683-93.

54. Chen S, Guo L, Chen B, Sun L, Cui M. Association of serum angiopoietin-1, angiopoietin-2 and angiopoietin-2 to angiopoietin-1 ratio with heart failure in patients with acute myocardial infarction. Exp Ther Med. 2013;5(3):937-41.

55. Johne B, Fagerhol MK, Lyberg T, Prydz H, Brandtzaeg P, Naess-Andresen CF, et al. Functional and clinical aspects of the myelomonocyte protein calprotectin. Mol Pathol. 1997;50(3):113-23.

56. Lusitani D, Malawista SE, Montgomery RR. Calprotectin, an Abundant Cytosolic Protein from Human Polymorphonuclear Leukocytes, Inhibits the Growth of Borrelia burgdorferi. Infection and Immunity. 2003;71(8):4711-6.

57. Cascone I, Napione L, Maniero F, Serini G, Bussolino F. Stable interaction between alpha5beta1 integrin and Tie2 tyrosine kinase receptor regulates endothelial cell response to Ang-1. J Cell Biol. 2005;170(6):993-1004.

58. Weber CC, Cai H, Ehrbar M, Kubota H, Martiny-Baron G, Weber W, et al. Effects of protein and gene transfer of the angiopoietin-1 fibrinogen-like receptor-binding domain on endothelial and vessel organization. J Biol Chem. 2005;280(23):22445-53.

59. Montagnana M, Danese E, Lippi G. Calprotectin and cardiovascular events. A narrative review. Clin Biochem. 2014;47(12):996-1001.

60. Srikrishna G. S100A8 and S100A9: new insights into their roles in malignancy. J Innate Immun. 2012;4(1):31-40.

61. Jensen LJ, Kistorp C, Bjerre M, Raymond I, Flyvbjerg A. Plasma calprotectin levels reflect disease severity in patients with chronic heart failure. Eur J Prev Cardiol. 2012;19(5):999-1004.

62. Ma LP, Haugen E, Ikemoto M, Fujita M, Terasaki F, Fu M. S100A8/A9 complex as a new biomarker in prediction of mortality in elderly patients with severe heart failure. Int J Cardiol. 2012;155(1):26-32.

63. Bachmann MP, Riva M, He Z, Källberg E, Ivars F, Leanderson T. Human S100A9 Protein Is Stabilized by Inflammatory Stimuli via the Formation of Proteolytically-Resistant Homodimers. PLoS ONE. 2013;8(4).

64. Stephan JR, Yu F, Costello RM, Bleier BS, Nolan EM. Oxidative Post-translational Modifications Accelerate Proteolytic Degradation of Calprotectin. Journal of the American Chemical Society. 2018;140(50):17444-55.

65. Chatzikonstantinou M, Konstantopoulos P, Stergiopoulos S, Kontzoglou K, Verikokos C, Perrea D, et al. Calprotectin as a diagnostic tool for inflammatory bowel diseases. Biomed Rep. 2016;5(4):403-7.

66. Corbin BD, Seeley EH, Raab A, Feldmann J, Miller MR, Torres VJ, et al. Metal chelation and inhibition of bacterial growth in tissue abscesses. Science. 2008;319(5865):962-5.

67. Grodin JL, Philips S, Mullens W, Nijst P, Martens P, Fang JC, et al. Prognostic implications of plasma volume status estimates in heart failure with preserved ejection fraction: insights from TOPCAT. Eur J Heart Fail. 2019. 
68. Pitt B, Pfeffer MA, Assmann SF, Boineau R, Anand IS, Claggett B, et al. Spironolactone for heart failure with preserved ejection fraction. N Engl J Med. 2014;370(15):1383-92.

69. Selvaraj S, Claggett B, Shah SJ, Anand I, Rouleau JL, O'Meara E, et al. Prognostic Value of Albuminuria and Influence of Spironolactone in Heart Failure With Preserved Ejection Fraction. Circ Heart Fail. 2018;11(11):e005288.

70. Lemieux C, Maliba R, Favier J, Theoret JF, Merhi Y, Sirois MG. Angiopoietins can directly activate endothelial cells and neutrophils to promote proinflammatory responses. Blood. 2005;105(4):152330.

71. Haddad LE, Sirois MG. Angiopoietin-1 upregulates de novo expression of IL-1beta and II1-Ra, and the exclusive release of II1-Ra from human neutrophils. PLoS One. 2014;9(2):e88980.

\section{Figures}

\section{Figure 1}

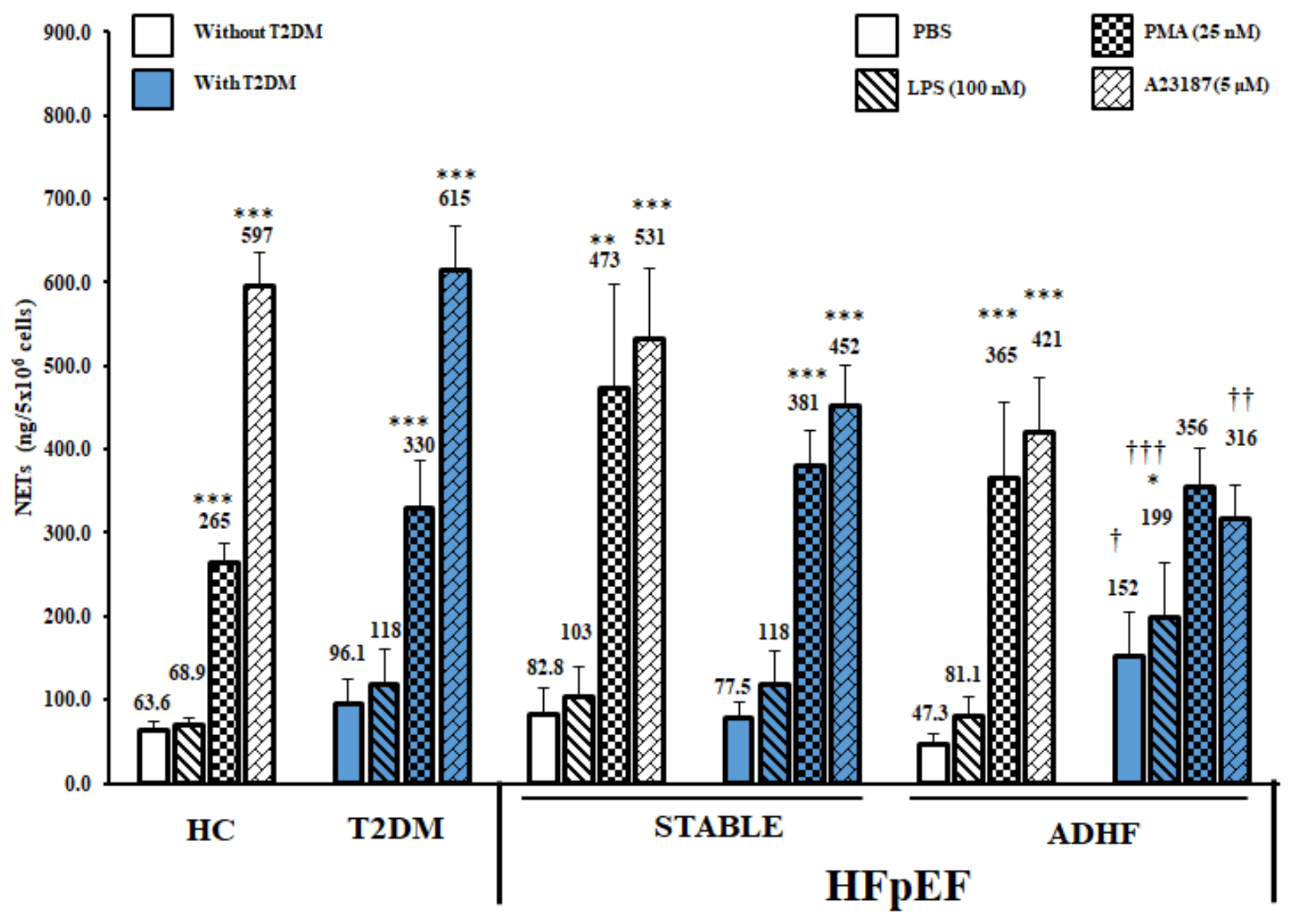

Figure 1 
NETs release by neutrophils. Isolated neutrophils $(5 \times 106 / \mathrm{mL})$ from HC, T2DM, stable HFpEF \pm T2DM and ADHFpEF \pm T2DM patients were incubated at $37^{\circ} \mathrm{C}$ for 3 hours with PBS (control vehicle) and agonists, LPS (100 nM), PMA (25 nM), or A23187 (5 $\mu \mathrm{M})$. NETs were quantified using Quant-IT PicoGreen dsDNA detection kit. Data shown as mean \pm SEM. Significance of data is indicated by ${ }^{*} p<0.05,{ }^{*} p<0.01$, and $\star \star * p<0.001$ compared with PBS respectively and by $+p<0.05$, $\uparrow+p<0.01$, $\uparrow+\uparrow p<0.001$ compared with corresponding treatment of HC. HC ( $n=28-32)$, T2D $(n=8)$, stable HFpEF $(n=5)$, stable HFpEF + T2DM $(n=6), \operatorname{ADHF}(n=6-7), \operatorname{ADHF}+\operatorname{T2DM}(n=5-6)$.

\section{Figure 2}

WGA

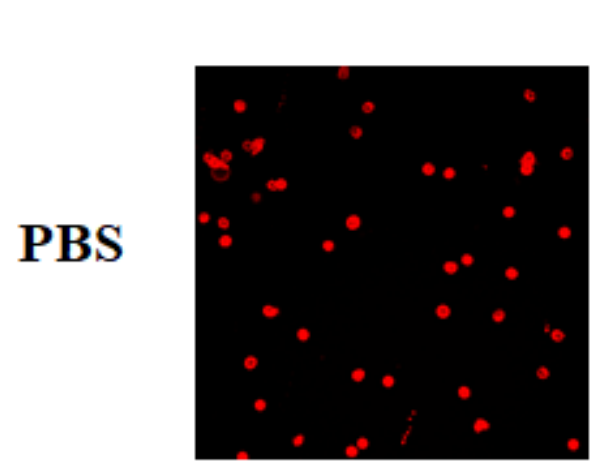

LPS

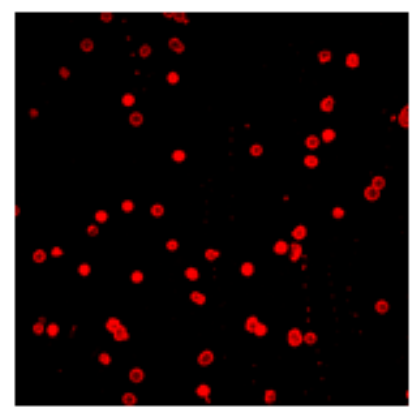

PMA

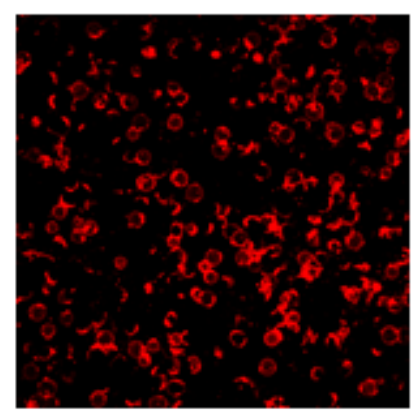

A23187

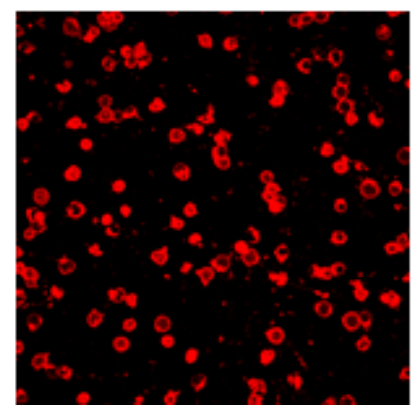

Sytox Orange
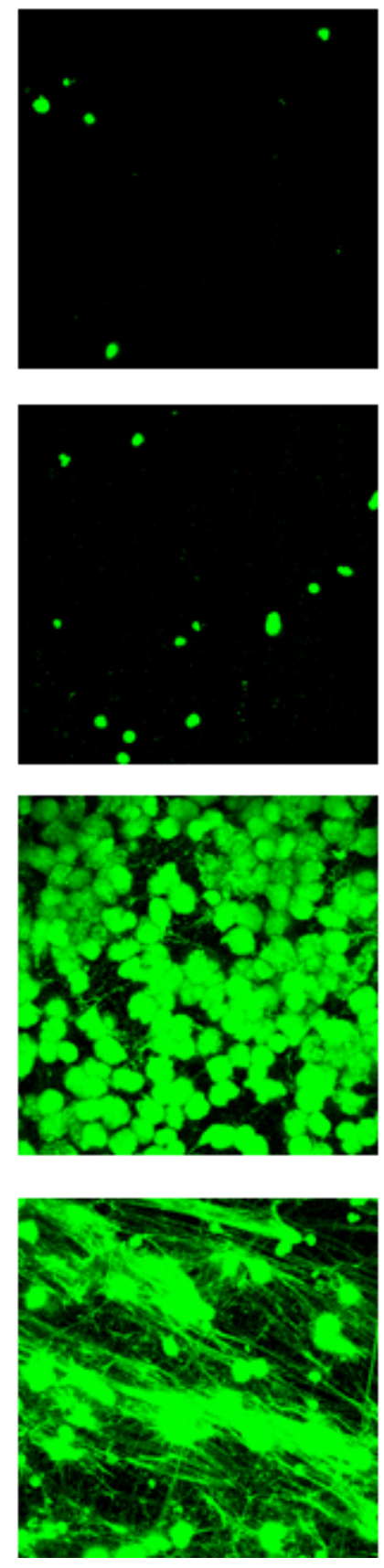

Antibody
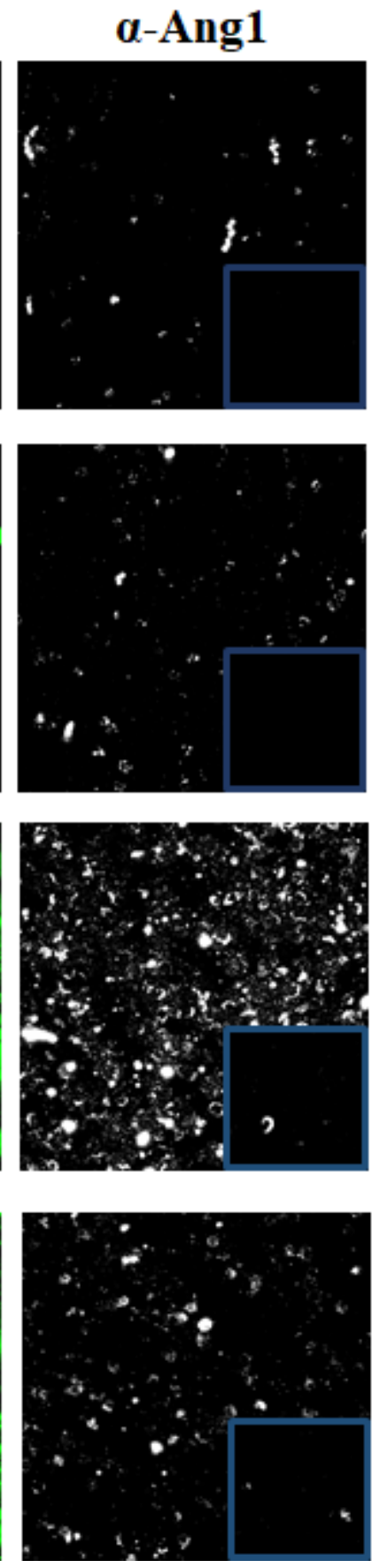

Merged

(3 images)
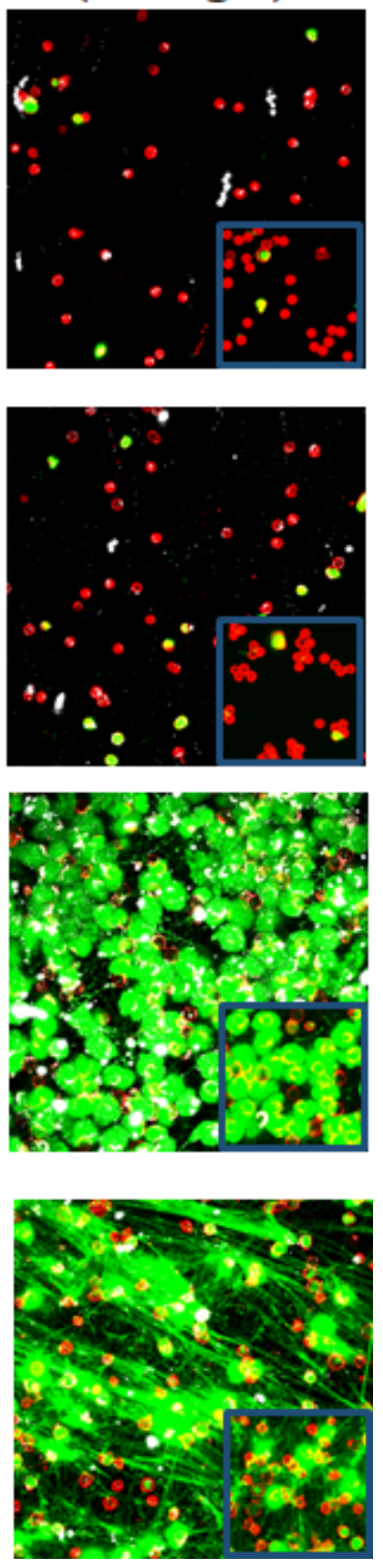


\section{Figure 2}

Ang1 is released independently from NETs. Neutrophils from healthy control $(\mathrm{HC})$ subjects were stimulated with PBS, LPS (100 nM), PMA (25 nM), or A23187 (5 $\mu \mathrm{M})$ for $3 \mathrm{~h}$ to induce NETosis. Following stimulation, neutrophils were incubated with a primary unconjugated Ab (Rabbit a-human Ang1), followed by an incubation with a conjugated secondary Ab (Alexa Fluor 488 goat anti-rabbit; white). For the negative control, neutrophils were incubated only with the secondary Ab (blue boxes). Neutrophils were labeled with wheat germ agglutinin (conjugated with Alexa 647; red) and NETs were labeled with SYTOX Orange (green). Maximum intensity projection from acquired Z-stack were obtained by confocal microscopy (LSM 710, Carl Zeiss) using a Plan Apochromat 40x/1.3 oil DIC objective. 


\section{Figure 3}

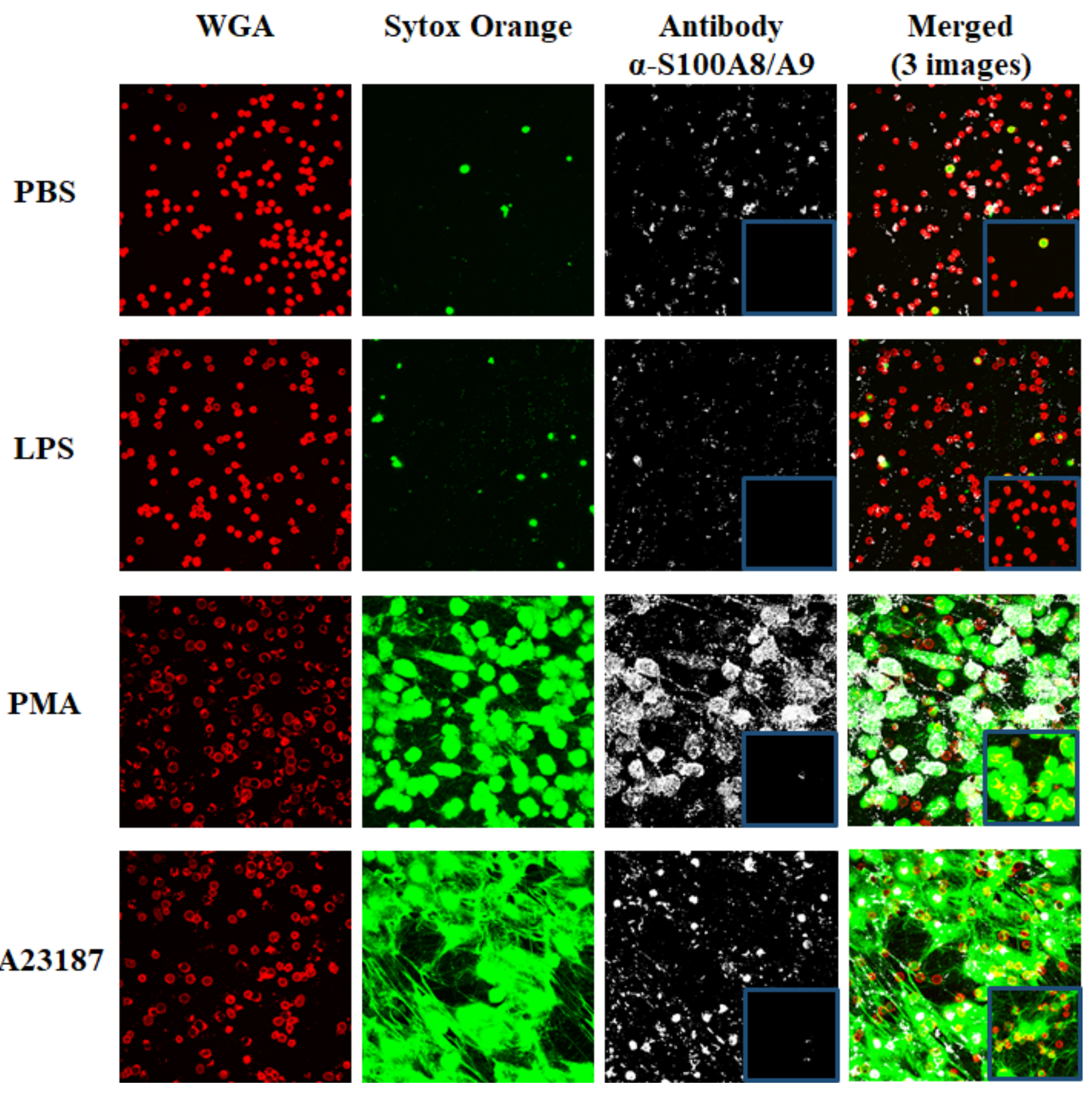

Figure 3

Calprotectin (S100A8/A9) binds to NETs. Neutrophils from healthy control (HC) subjects were stimulated with PBS, LPS (100 nM), PMA ( $25 \mathrm{nM})$, or A23187 ( $5 \mu \mathrm{M})$ for $3 \mathrm{~h}$ to induce NETosis. Following stimulation, neutrophils were incubated with a primary unconjugated $A b$ (mouse a-S100A8/A9), followed by followed by an incubation with a conjugated secondary Ab (Alexa Fluor 488 anti-mouse; white). For the negative control, neutrophils were incubated only with the secondary Ab (blue boxes). Neutrophils were labeled 
with wheat germ agglutinin (conjugated with Alexa 647; red) and NETs were labeled with SYTOX Orange (green). Maximum intensity projection from acquired Z-stack were obtained by confocal microscopy (LSM 710, Carl Zeiss) using a Plan Apochromat 40x/1.3 oil DIC objective.

\section{Figure 4}
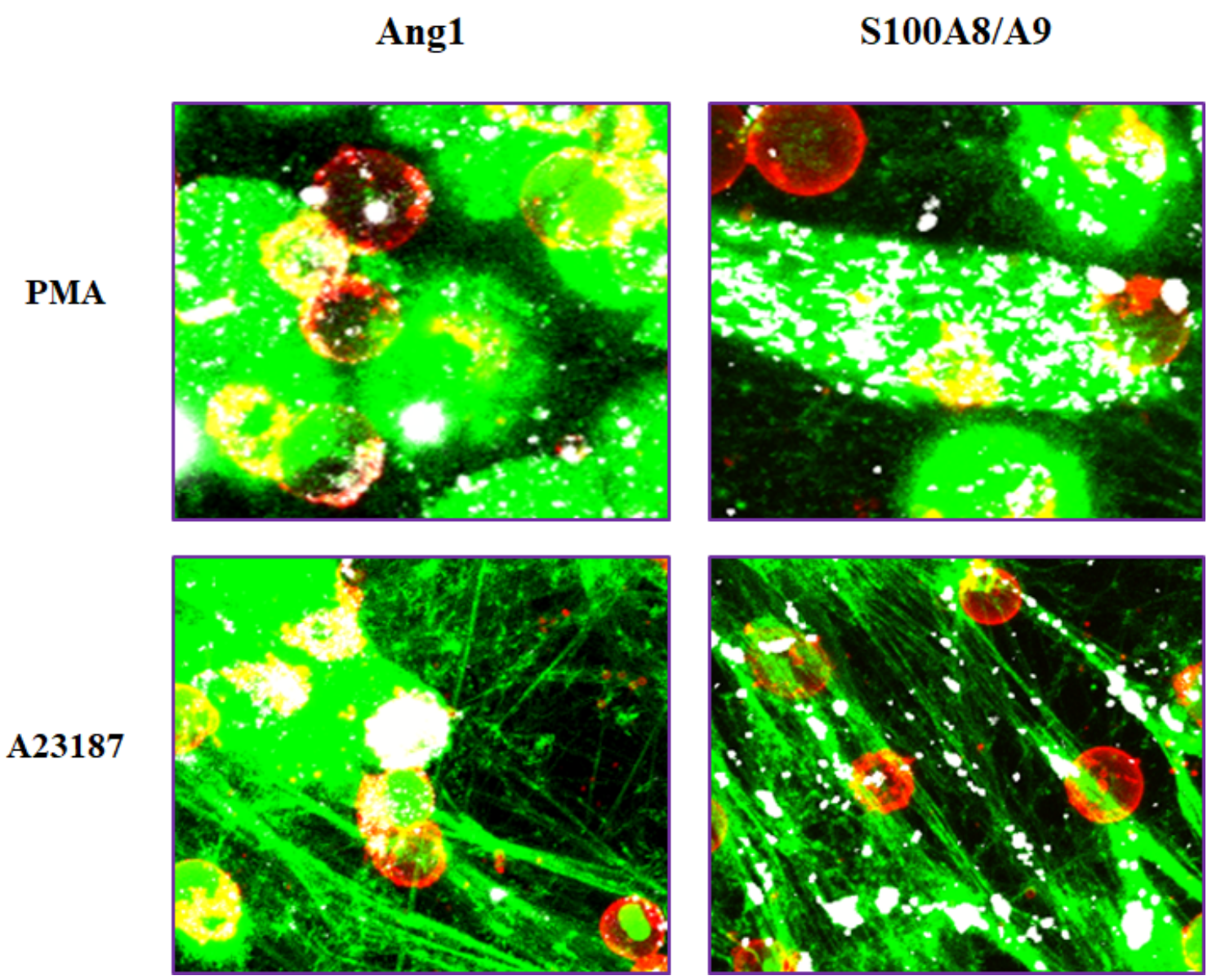

\section{Figure 4}

$\mathbf{A 2 3 1 8 7}$

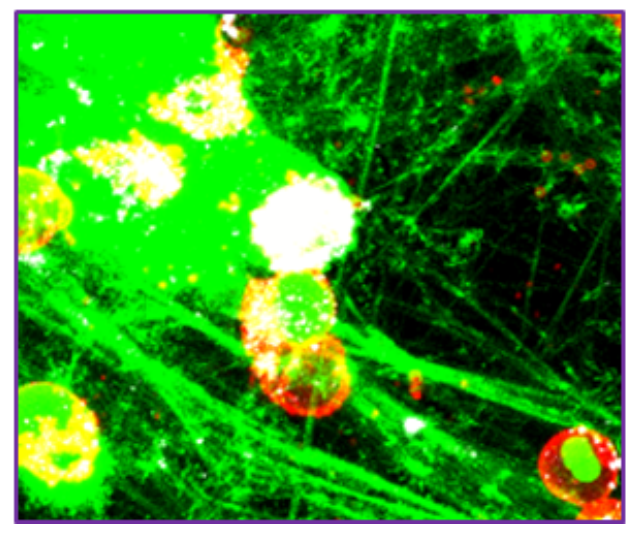

Ang1 and calprotectin interaction with NETs induced by PMA and A23187. These images are enlarged areas of the "Merged (3 images)" columns (PMA and A23187) from Figures 2 (Ang1) and 3 (calprotectin). We observe that Ang1 is mainly detected around the cells surface and does not interact with NETs, whereas calprotectin is detected either in the cells or on the NETs web-like structures.

\section{Supplementary Files}

This is a list of supplementary files associated with this preprint. Click to download.

- Charleset.al.RAWDATA.xIsx 